\title{
Foxp1 in Forebrain Pyramidal Neurons Controls Gene Expression Required for Spatial Learning and Synaptic Plasticity
}

\author{
Daniel J. Araujo, ${ }^{1}$-Kazuya Toriumi, ${ }^{1,4}{ }^{\circledR}$ Christine 0. Escamilla, ${ }^{2}$ Ashwinikumar Kulkarni, ${ }^{1}$ Ashley G. Anderson, ${ }^{1}$

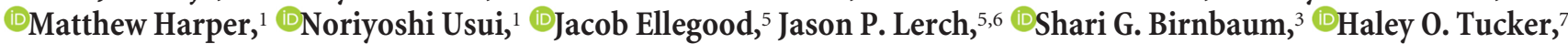 \\ (C) Craig M. Powell, ${ }^{1,2,3}$ and $\mathbb{C}^{-}$Genevieve Konopka ${ }^{1}$ \\ ${ }^{1}$ Department of Neuroscience, ${ }^{2}$ Department of Neurology, and ${ }^{3}$ Department of Psychiatry, University of Texas Southwestern Medical Center, Dallas, Texas \\ 75390, ${ }^{4}$ Project for Schizophrenia Research, Department of Psychiatry and Behavioral Sciences, Tokyo Metropolitan Institute of Medical Science, Tokyo \\ 156-8506, Japan, ${ }^{5}$ Mouse Imaging Centre, The Hospital for Sick Children, Toronto, Ontario M5T 3H7, Canada, ${ }^{6}$ Department of Medical Biophysics, University of \\ Toronto, Toronto, Ontario M5G 1L7, Canada, and ${ }^{7}$ University of Texas at Austin, Section of Molecular Genetics and Microbiology, Austin, Texas 78712
}

Genetic perturbations of the transcription factor Forkhead Box P1 (FOXP1) are causative for severe forms of autism spectrum disorder that are often comorbid with intellectual disability. Recent work has begun to reveal an important role for FoxP1 in brain development, but the brain-region-specific contributions of Foxp1 to autism and intellectual disability phenotypes have yet to be determined fully. Here, we describe Foxp1 conditional knock-out $\left(F o x p 1^{\mathrm{cKO}}\right)$ male and female mice with loss of Foxp1 in the pyramidal neurons of the neocortex and the CA1/CA2 subfields of the hippocampus. Foxp $1^{\mathrm{cKO}}$ mice exhibit behavioral phenotypes that are of potential relevance to autism spectrum disorder, including hyperactivity, increased anxiety, communication impairments, and decreased sociability. In addition, Foxp $1^{\text {cKO }}$ mice have gross deficits in learning and memory tasks of relevance to intellectual disability. Using a genome-wide approach, we identified differentially expressed genes in the hippocampus of Foxp $1^{\mathrm{cKO}}$ mice associated with synaptic function and development. Furthermore, using magnetic resonance imaging, we uncovered a significant reduction in the volumes of both the entire hippocampus as well as individual hippocampal subfields of $\operatorname{Foxp}_{1}^{\mathrm{CKO}}$ mice. Finally, we observed reduced maintenance of LTP in area CA1 of the hippocampus in these mutant mice. Together, these data suggest that proper expression of Foxp1 in the pyramidal neurons of the forebrain is important for regulating gene expression pathways that contribute to specific behaviors reminiscent of those seen in autism and intellectual disability. In particular, Foxp1 regulation of gene expression appears to be crucial for normal hippocampal development, CA1 plasticity, and spatial learning.

Key words: autism; gene expression; hippocampus; spatial learning; synaptic plasticity

Significance Statement

Loss-of-function mutations in the transcription factor Forkhead Box P1 (FOXP1) lead to autism spectrum disorder and intellectual disability. Understanding the potential brain-region-specific contributions of FOXP1 to disease-relevant phenotypes could be a critical first step in the management of patients with these mutations. Here, we report that Foxpl conditional knock-out $\left(\right.$ Foxp $\left.{ }^{\mathrm{cKO}}\right)$ mice with loss of Foxp1 in the neocortex and hippocampus display autism and intellectual-disability-relevant behaviors. We also show that these phenotypes correlate with changes in both the genomic and physiological profiles of the hippocampus in Foxp ${ }^{\text {cKO }}$ mice. Our work demonstrates that brain-region-specific FOXP1 expression may relate to distinct, clinically relevant phenotypes.

\section{Introduction}

Autism spectrum disorder (ASD) is often comorbid with intellectual disability (ID) (Geschwind and State, 2015; de la TorreUbieta et al., 2016). Delineating the brain circuits that contribute

Received April 13, 2017; revised Sept. 12, 2017; accepted Sept. 14, 2017.

Author contributions: D.J.A., C.M.P., and G.K. designed research; D.J.A., K.T., C.O.E., A.K., A.G.A., M.H., N.U., J.E., and S.G.B. performed research; H.O.T. contributed unpublished reagents/analytic tools; D.J.A., J.E., J.P.L., C.M.P., and G.K. analyzed data; D.J.A. and G.K. wrote the paper. to distinct ASD and ID symptoms could be a major first step toward improved treatments for these disorders. ASD has a strong genetic component (Geschwind and State, 2015; de la Torre-Ubieta et al., 2016) that is shared in part with ID (Vissers et 
al., 2016). Numerous transcription factors coordinate the expression patterns of ASD and ID risk genes during early brain development (State and Šestan, 2012; de la Torre-Ubieta et al., 2016). Therefore, investigating the role of ASD- and ID-relevant transcription factors in a brain-region-specific manner could reveal circuit-based pathways that contribute to discrete behavioral phenotypes in the two disorders.

Heterozygous mutations and deletions in the transcription factor Forkhead Box P1 (FOXP1) are causative for ASD and ID (Bacon and Rappold, 2012; Le Fevre et al., 2013; Lozano et al., 2015; Vissers et al., 2016). In addition, FOXP1 has been classified as a high-confidence ASD and ID risk gene in several recent, large-scale sequencing studies (Iossifov et al., 2014; Sanders et al., 2015; Stessman et al., 2017). FOXP1 is a member of the Forkhead Box (FOX) transcription factor family, which is denoted by a unique nomenclature (uppercase for primates, title case for rodents, and mixed case for all other species or collection of species; Kaestner et al., 2000).

Within the forebrain, Foxp 1 expression is largely restricted to the pyramidal neurons of the neocortex and the CA1/CA2 hippocampal subfields, as well the medium spiny neurons of the striatum (Ferland et al., 2003; Tamura et al., 2004; Hisaoka et al., 2010). Conditional, full-brain loss of Foxp1 results in altered social behaviors, impaired learning and memory, and developmental aberrations in the striatum (Bacon et al., 2015). Neocortical knock-down of Foxp1 disrupts neuronal migration and axon formation, but the resultant behavioral phenotypes have not been assessed (Li et al., 2015). Finally, using a patient-relevant heterozygous Foxp1 knock-out mouse, we have shown that Foxp1 regulates distinct, regional transcriptional profiles in the brain and that loss of Foxp1 expression in the striatum strongly correlates with deficits in ultrasonic vocalization production (Araujo et al., 2015). Although these studies have begun to shed light on the function of Foxp1 within the brain, the specific contributions of neocortical and hippocampal Foxp 1 to the ASD and ID phenotypes remain to be determined. Addressing this question is important, given that many changes to the anatomy, transcriptional profiles, and physiology of the neocortex and hippocampus are observed in ASD and ID brains (Chen et al., 2015).

To investigate the regional contributions of Foxp1 expression to ASD- and ID-relevant phenotypes, we used an Emx1.Cre mouse line (Gorski et al., 2002) to generate a Foxp1 conditional knockout $\left(\right.$ Foxp $\left.1^{\mathrm{cKO}}\right)$ mouse with loss of Foxp1 in the pyramidal neurons of the neocortex and the hippocampus. In this study, we integrate behavioral profiling, electrophysiology, magnetic resonance imaging (MRI) analyses, and genomics. We show that loss of Foxp1 in the neocortex and hippocampus is sufficient to produce ASD- and ID-relevant behaviors such as hyperactivity, communication deficits, decreased sociability, and impaired spatial

to C.M.P.); the Uehara Memorial Foundation (N.U.); the Ontario Brain Institute (J.P.L.), Brain Canada (J.P.L.), and the Canadian Institute for Health Research (J.P.L.); the University of Texas Southwestern Jon Heighten Scholar in Autism Research Endowment (G.K.); and the Simons Foundation Autism Research Initiative (Project 401220 to G.K.). We thank Drs. Courtney Lane, Irene Masiulis Bowen, and Joachim Herz for assistance with data collection and experimental design and Drs. Amelia Eisch, Lenora Volk, and Jiang Wu for providing valuable comments on this study.

The authors declare no competing financial interests.

N. Usui's present address: Division of Development of Mental Functions, Research Center for Child Mental Development, University of Fukui, Fukui, Japan; Division of Developmental Higher Brain Functions, Department of Child Development, United Graduate School of Child Development, Osaka University, Kanazawa University, Hamamatsu University School of Medicine, Chiba University and University of Fukui, Osaka, Japan.

Correspondence should be addressed to Genevieve Konopka, Ph.D., Department of Neuroscience, UT Southwestern Medical Center, 5323 Harry Hines Blvd., ND4.300, Dallas, TX 75390-9111. E-mail: genevieve.konopka@utsouthwestern.edu.

DOI:10.1523/JNEUROSCI.1005-17.2017

Copyright $\odot 2017$ the authors $\quad 0270-6474 / 17 / 3710918-15 \$ 15.00 / 0$ learning and memory. In addition, we show that the ID-like learning and memory deficits observed in Foxp $1^{\text {cKO }}$ mice are likely due to alterations in hippocampal function because behaviors involving broader cortical circuits are unaffected. Using RNA-sequencing (RNA-seq), we correlate these behavioral phenotypes to specific changes in the transcriptome of the Foxp $1^{\text {cKO }}$ hippocampus. We also use MRI to demonstrate that loss of forebrain Foxp1 expression leads to decreased hippocampal volumes. Finally, based on the genomic and morphological data, we assayed the electrophysiological properties of the Foxp1 $1^{\mathrm{cKO}}$ hippocampus and found reduced CA1-dependent LTP maintenance. As a whole, our data suggest that certain behavioral consequences of Foxp1 loss can be attributed to disrupted gene networks within distinct regions of the brain. Therefore, these data could lead to improved treatments for specific ASD and ID symptoms.

\section{Materials and Methods}

Mice. Homozygous-floxed Foxp1 (Foxp $1^{\text {flox/flox }}$ ) mice (Feng et al., 2010) were backcrossed with C57BL/6J mice for at least 10 generations to obtain congenic animals. Mice hemizygous for Cre recombinase expression under the control of the Emxl promoter (Emxl.Cre ${ }^{+1-}$ mice) (Gorski et al., 2002) were purchased from The Jackson Laboratory (strain \#005628) and are congenic for the C57BL/6J background. Experimental animals were generated by crossing male Emx1.Cre ${ }^{+/-} ;$Foxp $1^{\text {flox/flox }}$ mice with female Foxp $1^{\text {flox/flox }}$ mice. Mice were kept in the animal facilities of the University of Texas (UT) Southwestern Medical Center under a $12 \mathrm{~h}$ light/dark cycle and all behavioral testing occurred during the light cycle with the experimenter blinded to genotype. Unless otherwise specified, all mice were given ad libitum access to food and water. All mouse studies were approved by the UT Southwestern Institutional Animal Care and Use Committee.

Immunoblotting. Regional brain lysates from adult ( $>8$ weeks old) male mice were prepared and used in immunoblotting experiments as described previously (Araujo et al., 2015).

Tissue preparation. For immunohistochemistry, adult female and male mice were anesthetized with $80-100 \mathrm{mg} / \mathrm{kg}$ Euthasol (UT Southwestern Medical Center Animal Resources Center Veterinary Drug Services), perfused with PBS containing $10 \mathrm{U} / \mathrm{ml}$ heparin (Sigma-Aldrich) followed by fixative (4\% PFA in PBS), and then immediately decapitated. Whole brains were removed and incubated in fixative for $24 \mathrm{~h}$ at $4^{\circ} \mathrm{C}$ and then incubated in $30 \%$ sucrose (made in PBS with $0.02 \%$ sodium azide) for $24-48 \mathrm{~h}$ at $4^{\circ} \mathrm{C}$. Afterward, brains were sectioned at $35-40 \mu \mathrm{m}$ on an SM2000 R sliding microtome (Leica). Sections were then stored in PBS containing $0.02 \%$ sodium azide until being used in immunohistochemistry.

For MRI, adult male mice were anesthetized with $80-100 \mathrm{mg} / \mathrm{kg} \mathrm{Eu}-$ thasol, perfused with PBS (without $\mathrm{Ca}^{2+}$ and $\mathrm{Mg}^{2+}$ ) containing $10 \mathrm{U} / \mathrm{ml}$ heparin and $2 \mathrm{~mm}$ ProHance (Bracco Diagnostics), and then fixative (4\% PFA in PBS without $\mathrm{Ca}^{2+}$ and $\mathrm{Mg}^{2+}$ ) containing $2 \mathrm{~mm}$ ProHance. Animals were then immediately decapitated and the cartilaginous nose tip, eyes, skin, lower jar, ears, and zygomatic bones were removed. Brains (encased in the remaining skull structures) were then incubated in fixative containing $2 \mathrm{~mm}$ ProHance and $0.02 \%$ sodium azide for $24 \mathrm{~h}$ at $4^{\circ} \mathrm{C}$ and subsequently transferred to PBS (without $\mathrm{Ca}^{2+}$ and $\mathrm{Mg}^{2+}$ ) containing $2 \mathrm{~mm}$ ProHance and $0.02 \%$ sodium azide for storage at $4^{\circ} \mathrm{C}$.

Immunohistochemistry. Floating immunohistochemistry was performed according to standard procedures. Briefly, at room temperature, sections were first washed with TBS. Next, they were incubated with $3 \%$ hydrogen peroxide for $30 \mathrm{~min}$, washed with TBS, treated with $0.3 \mathrm{M}$ glycine for $30 \mathrm{~min}$, and washed again with TBS. Sections were then incubated with primary antibodies diluted in TBS-T $(0.4 \%$ Triton X-100) containing $1 \%$ bovine serum albumin (BSA) and 3\% normal donkey serum (NDS) overnight at $4^{\circ} \mathrm{C}$. Next, sections were washed in TBS-T, incubated with secondary antibodies diluted in TBS-T containing $1 \%$ BSA and 3\% NDS for $1 \mathrm{~h}$ at room temperature, and then mounted onto microscope slides. Finally, slides were washed with TBS-T and allowed to dry overnight at room temperature, mounted with ProLong Diamond Antifade Mountant with DAPI (Thermo Fisher Scientific) and a cover- 
slip, and allowed to set overnight at room temperature. Slides were imaged using an LSM 710 Confocal Microscope (Zeiss) connected to a computer running Zen 2012 Software (Zeiss).

Magnetic resonance imaging. A multichannel 7.0 tesla MRI scanner (Agilent Technologies) was used to image the brains within skulls. Sixteen custom-built solenoid coils were used to image the brains in parallel (Bock et al., 2005; Lerch et al., 2011). A T2-weighted 3D fast spin echo (FSE) sequence was used for the acquisition of the anatomical images. Parameters for the FSE sequence were as follows: TR of $350 \mathrm{~ms}$ and TEs of 12 ms per echo for 6 echoes, 2 averages, field of view of $20 \times 20 \times 25$ $\mathrm{mm}^{3}$, and a matrix size of $504 \times 504 \times 630$, giving an image with $40 \mu \mathrm{m}$ isotropic resolution. $\mathrm{K}$-space was acquired with a cylindrical acquisition (Nieman et al., 2005). Total imaging time was $14 \mathrm{~h}$. To visualize and compare any changes in the mouse brains, the images were linearly (six parameter followed a 12 parameter) and nonlinearly registered together. All scans were then resampled with the appropriate transform and averaged to create a population atlas representing the average anatomy of the study sample. The result of the registration was to have all scans deformed into alignment with each other in an unbiased fashion. This allows for the analysis of the deformations needed to take each individual mouse's anatomy into this final atlas space, the goal being to model how the deformation fields relate to genotype (Nieman et al., 2006; Lerch et al., 2008). The Jacobian determinants of the deformation fields are then calculated as measures of volume at each voxel. Significant volume changes can then be calculated by warping a preexisting classified MRI atlas onto the population atlas, which allows for the volume of 159 segmented structures encompassing cortical lobes, large white matter structures (i.e., corpus callosum), ventricles, cerebellum, brainstem, and olfactory bulbs to be assessed in all brains. This atlas is a combination of three separate atlases (Dorr et al., 2008; Ullmann et al., 2013; Steadman et al., 2014). In addition to the regional assessment, these images can be examined on a voxelwise basis to localize the differences found within regions or across the brain. Multiple comparisons in this study were controlled for using the false discovery rate (FDR) (Genovese et al., 2002).

Antibodies. The following antibodies were used for immunoblotting (IB) or immunohistochemistry (IHC): anti-Foxp1 (Spiteri et al., 2007; rabbit; 1:5000 for IB, 1:1000 for IHC) and anti-GAPDH (mouse, Millipore; 1:5000 for IB).

$R N A$ processing. RNA purification was performed on tissues dissected from postnatal day 47 FoxplcKO mice and littermate controls as described previously (Araujo et al., 2015).

$q P C R$. qPCR was performed as described previously (Araujo et al., 2015). All primer sequences are available upon request.

RNA-seq library preparation. RNA-seq library preparation was performed according to previously published methods (Takahashi et al., 2015). Briefly, mRNA was isolated from $2 \mu \mathrm{g}$ of total RNA (at RIN values $\geq 8.9$ ) harvested from adult tissues via poly(A) selection. Fifteen PCR cycles were used for cDNA amplification. Pooled libraries, each at a final concentration of $2 \mathrm{~nm}$, were sequenced on a NextSeq 500 Sequencer (Illumina) by the McDermott Sequencing Core at UT Southwestern Medical Center to generate single-end 75 bp reads.

RNA-seq data analysis. Raw reads were first filtered for phred quality and adapters using FASTQC (Andrews, 2010) and Trimmomatic (Bolger et al., 2014). Filtered reads were then aligned to the reference mouse genome mm10 (https://genome.ucsc.edu) using STAR (Dobin et al., 2013) aligner. Uniquely mapped reads were used to obtain the gene counts using HTSeq package (Anders et al., 2015) and the read counts were normalized using the CPM (counts per million) method implemented in the edgeR package (Robinson et al., 2010; McCarthy et al., 2012). For further analysis, we performed a sample-specific CPM filtering, considering genes with CPM values of 1.0 in all replicates for treatments or controls. DESeq (Anders and Huber, 2010; Love et al., 2014) was used to detect the differentially expressed genes (DEGs). We applied a filter of an adjusted $p$-value of $\leq 0.005$ and absolute log fold change of $\geq 0.3$ to identify DEGs.

DEG gene ontology (GO) analysis. GO analysis of the significant DEGs was performed using ToppGene (https://toppgene.cchmc.org) and GO terms were reduced using REVIGO (Supek et al., 2011). GO categories were considered significant if they contained at least three genes and if they had a Benjamini-Hochberg (Benjamini-Hochberg)-corrected $p$-value and $q$-value of $\leq 0.05$.

Weighted gene coexpression network analysis. Weighted gene coexpression network analysis (WGCNA) was performed on 16 total RNA-seq samples (8 neocortical samples: 4 control, 4 Foxp $1^{\text {cKO }}$ and 8 hippocampal samples: 4 control, 4 Foxp $1^{\mathrm{cKO}}$ ). The R package for WGCNA (Langfelder and Horvath, 2008) was used to build gene coexpression network using filtered CPM data (CPM $>=1$ across all replicates of a condition). A signed network was constructed using blockwiseModules function of the WGCNA R package. A value of 10 was chosen as Beta with highest scale-free R square $\left(R^{2}=0.8\right)$. For other parameters, we used corType $=$ pearson, maxBlockSize $=15000$, reassignThreshold $=1 \times 10^{-6}$, mergeCutHeight $=0.1$, deepSplit $=4$, and detectCutHeight $=0.999 . \mathrm{Vi}-$ sualizations of network plots were created using Cytoscape v3.4.0 (Shannon et al., 2003), representing the top 500 edges based on ranked weights.

Hippocampal electrophysiology. An experimenter blinded to genotype performed all electrophysiology studies. Juvenile (6-7 weeks old) male mice were anesthetized briefly with isoflurane (Baxter Healthcare) and rapidly decapitated to remove the brain, which was then submerged in ice-cold ACSF containing the following (in mM): 75 sucrose, $87 \mathrm{NaCl}$, $3 \mathrm{KCl}, 1.25 \mathrm{NaH}_{2} \mathrm{PO}_{4}, 7 \mathrm{MgSO}_{4}, 26 \mathrm{NaHCO}_{3}, 20$ dextrose, and $0.5 \mathrm{CaCl}_{2}$. Acute coronal hippocampal slices were cut $350 \mu \mathrm{m}$ thick using a VT $1000 \mathrm{~S}$ vibrating microtome (Leica). To reduce recurrent excitation of CA3 neurons, a cut was made between $\mathrm{CA} 3$ and CA1. Slices were allowed to recover at $34^{\circ} \mathrm{C}$ for $15 \mathrm{~min}$ in normal ACSF containing the following (in $\mathrm{mm}): 124 \mathrm{NaCl}, 5 \mathrm{KCl}, 1.25 \mathrm{NaH}_{2} \mathrm{PO}_{4}, 2 \mathrm{MgCl}_{2}, 26 \mathrm{NaHCO}_{3}, 10$ dextrose, and $1 \mathrm{CaCl}_{2}$. Recovery continued for $45 \mathrm{~min}$ as slices were gradually cooled to room temperature for holding before recording. All solutions were $\mathrm{pH} 7.4$ and saturated with $95 \% \mathrm{O}_{2} / 5 \% \mathrm{CO}_{2}$.

All recordings were performed at $33^{\circ} \mathrm{C} \pm 0.5^{\circ} \mathrm{C}$ in ACSF containing the following (in mM): $124 \mathrm{NaCl}, 5 \mathrm{KCl}, 1.25 \mathrm{NaH}_{2} \mathrm{PO}_{4}, 1 \mathrm{MgCl}_{2}, 26$ $\mathrm{NaHCO}_{3}, 10$ dextrose, and $2 \mathrm{CaCl}_{2}$ saturated with $95 \% \mathrm{O}_{2} / 5 \% \mathrm{CO}_{2}$ and all data were collected using Clampex (pClamp Software Suite 10.2; Molecular Devices). Recordings were filtered at $1 \mathrm{kHz}$ and digitized at 10 $\mathrm{kHz}$. CA3-CA1 synapses were stimulated by a $100 \mu$ s biphasic pulse through custom-made nickel dichromate electrodes (A-M Systems) placed $400-500 \mu \mathrm{m}$ laterally from the recording electrode and kept constant within this range for all experiments. Stimulation was controlled using a model 2200 stimulus isolator (A-M Systems). The recording electrode (1-3 M $\Omega$ ) was filled with normal ACSF and placed in the stratum radiatum using a SZX7 dissecting microscope (Olympus) at $35 \times$ magnification. Sample size for all extracellular field recordings represents number of slices tested with two to four slices used per mouse. Response size was determined by fitting a straight line to the initial slope (10-40\%) of the field EPSP (fEPSP) using automated analysis in Clampfit (pClamp Software Suite 10.2; Molecular Devices). For LTP, the stimulus intensity was set to generate $\sim 50 \%$ of the maximum fEPSP, as determined by the input/output curve. LTP was induced with 2 trains of $100 \mathrm{~Hz}$ stimulation for $1 \mathrm{~s} \mathrm{separated} \mathrm{by} 1 \mathrm{~min}$. A $20 \mathrm{~min}$ baseline was recorded before LTP induction and followed by at least $60 \mathrm{~min}$ of $0.05 \mathrm{~Hz}$ stimulation (every $20 \mathrm{~s}$ ).

Novel cage activity test. Adult male and female mice were moved individually from their home cages into clean, plastic $(18 \times 28 \mathrm{~cm})$ cages with minimal bedding. Each cage was then placed into a dark Plexiglas box. Movement was measured with Photobeam Activity System-Home Cage software (San Diego Instruments) for $2 \mathrm{~h}$ for each mouse. The number of beam breaks was recorded every $5 \mathrm{~min}$.

Open-field test. The open-field assay was performed on adult male and female mice as described previously (Araujo et al., 2015).

Ultrasonic vocalizations. Ultrasonic vocalizations produced by adult male mice were assessed in a mating paradigm modified from previously published methods (Holy and Guo, 2005). Briefly, male mice were singly paired with age-matched C57BL/6J female mice for 1 week. Afterward, female mice were removed from the cages and the males were housed singly for 1 week. The next day (the test day), the male mice were allowed to habituate to the testing environment for $15 \mathrm{~min}$. During habituation, food hoppers were removed and the cage lids were replaced with Styrofoam lids containing UltraSoundGate condenser microphones (Avisoft Bioacoustics) positioned at a fixed height. The condenser microphones were connected to UltraSoundGate416H hardware (Avisoft Bioacous- 
tics) hooked up to a computer running RECORDER software (Avisoft Bioacoustics). Next, habituated, age-matched C57BL/6J female mice were placed randomly into a cage containing a male. The resultant male songs were recorded for $3 \mathrm{~min}$. No female was used in $>2$ recording sessions per day. Analyses of ultrasonic vocalization features were performed as described previously (Araujo et al., 2015). Call duration reflects the average length of calls (in milliseconds), mean frequency denotes the average frequency of calls (in kilohertz), frequency range is the average difference between the maximum and minimum frequency at which calls are produced (in kilohertz), the fraction of calls with frequency jumps represents the ratio of calls with and without frequency breaks, and the average slope of the call reflects modulation of call frequency over time (in hertz/milliseconds).

Social interaction test. Adult female and male mice were placed individually in an open-field environment $(44 \times 44 \mathrm{~cm}$ with walls $30 \mathrm{~cm}$ high) in a dimly lit room and allowed to explore for $5 \mathrm{~min}$. Inside the open-field arena, a small plastic chamber (the interaction box, $8.5 \times 4.5$ $\mathrm{cm}$ ) was placed along one wall of the arena. After $5 \mathrm{~min}$, the test mouse was removed and a novel, unfamiliar mouse (same sex and strain as the test mouse) was placed into the interaction box. Small holes in the interaction box allow the mice to see, hear, and smell each other. The test mouse was returned to the open-field environment and allowed to explore for another $5 \mathrm{~min}$. The test mouse was monitored from above by a video camera connected to a computer running Ethovision 3.0 (Noldus). Both the amount of time the test mouse spent in the interaction zone immediately adjacent to the interaction chamber (within $8 \mathrm{~cm}$ ) and the time spent in the four corners of the arena $(9 \times 9 \mathrm{~cm}$ each) were recorded.

Nesting behavior. Nesting behavior was gauged in adult male and female mice as described previously (Araujo et al., 2015).

Fear conditioning. Fear conditioning was conducted on adult female and male animals using boxes containing a grid metal floor attached to a scrambled shock generator. Mice were individually trained by placing them into the box for $2 \mathrm{~min}$ and giving them 3 separate tone-shock pairings ( $30 \mathrm{~s}$ white noise, followed by a $2 \mathrm{~s}, 0.5 \mathrm{~mA}$ shock, with $1 \mathrm{~min}$ intervals between pairings). Context recall was assessed $24 \mathrm{~h}$ later by placing the mice back into the original box and recording freezing for $5 \mathrm{~min}$. Cue recall was assessed $2 \mathrm{~d}$ after training by placing the mice in boxes that were altered with a plastic floor, an inverted roof, and a vanilla scent. Freezing was then measured for $3 \mathrm{~min}$, followed by the presentation of the white noise cue and measuring freezing for an additional 3 min with Video Freeze software (Med Associates).

Morris water maze. The Morris water maze was conducted on adult male mice using a $1.2-\mathrm{m}$-diameter circular pool filled with opaque, tempera-paint-dyed $23^{\circ} \mathrm{C}$ water. Stark visual cues were placed around the room containing the pool. Within the pool, a $10 \mathrm{~cm}$ circular Plexiglas escape platform was submerged in one of the quadrants $1 \mathrm{~cm}$ below the water's surface. For training, mice were placed into the pool in one of four starting locations (north, south, east, or west, with the order determined randomly) and allowed to swim until they located the escape platform. Upon finding the platform, mice were permitted to rest for $5 \mathrm{~s}$ before being removed. If they did not locate the platform within $60 \mathrm{~s}$, mice were guided manually to the platform and given $5 \mathrm{~s}$ of rest before being removed. Mice received four training trials per day for $10 \mathrm{~d}$ and were placed in temporary cages between the training trials of a particular day. On day 12 , after a day of rest on day 11 , a probe test was performed in which mice were allowed to swim in the pool for $60 \mathrm{~s}$, with the escape platform removed. The movements of the animals were recorded by a video camera centered above the pool and tracked using ANY-Maze software (Stoelting). The latency to reach the escape platform was quantified for each mouse during the $10 \mathrm{~d}$ training period. For the probe test, the number of original platform crosses was analyzed for each mouse.

T-maze. The T-maze was constructed from gray polyvinyl, with the main array $40 \mathrm{~cm}$ long, the side arms $33 \mathrm{~cm}$ long, the walls $18.5 \mathrm{~cm}$ high, and the alleys $10 \mathrm{~cm}$ wide (Actimetrics). Before commencing any testing, adult female and male mice were subjected to food restriction until their body weight reached $85 \%$ of baseline. Then, for habituation to the T-maze, each mouse was placed into the apparatus with all of the doors open and a food pellet (20 mg; Bio-Serv) placed in a cup at the end of each arm. This was performed in 4 sessions, each 10 min long, for $2 \mathrm{~d}$. After this habituation period, each mouse was used in 10 test trials per day for 10 consecutive days. For the testing phase, each trial was composed of two different runs: the sample run and the test run. In the sample run, the pellet reward was placed randomly at one end of the arms and the other arm was closed off. A mouse was then placed at the start position and allowed to travel freely to the end of the arm and consume the pellet. Immediately after consuming the pellet, the mouse was placed back in the start position, which was closed off. While the mouse was isolated in the start position, the blocked arm was opened and the entire apparatus was wiped with $10 \%$ ethanol to remove olfactory cues. A food pellet was then placed in the arm opposite from the one containing the reward in the sample run. After a 30 s delay, the test run was started. In the test run, each mouse was allowed to travel to either arm. If the mouse chose the opposite arm that was rewarded in the sample run (a correct choice), then it was allowed to consume the pellet. If the mouse chose the same arm as in the sample run (an incorrect choice), then it was blocked in the arm for $30 \mathrm{~s}$ as punishment. Spatial working memory was evaluated by the average success rate for each day.

Set-shifting task. With minor modifications, the set-shifting test was conducted as described previously (Cho et al., 2015). Before testing began, adult male and female mice were subjected to food restriction until their body weight reached $85 \%$ of baseline. Afterward, animals were housed individually and then presented with two bowls in their home cage until they began digging in one bowl. Each of these bowls contained a different odor and a different digging medium and the odor-medium combinations were altered and counterbalanced from trial to trial. The digging media were white calcium sand and pine wood shavings mixed with an odorant (ground garlic or clove $0.01 \%$ by volume) and peanut butter chip powder $(0.1 \%$ by volume). The reward, a $5-10 \mathrm{mg}$ piece of a peanut butter chip, was buried in the medium in both of the food bowls.

Testing began once mice reached their target weight. The testing procedure consisted of three phases (training, initial association, and ruleshift), with each phase lasting $1 \mathrm{~d}$ for a total of 3 consecutive days. On day 1 (the training day), mice were given 10 consecutive trials in which they were allowed to dig among two bowls containing two different mediums to learn that they could reliably find a food reward in only one of the bowls. On day 2 (the initial association day), mice learned that a specific cue (an odor or medium) predicted the presence of food reward by being presented with different odor-medium combinations (which were switched and counterbalanced) during each trial. This predictive cue remained constant over the whole day, with each mouse being randomly assigned their own cue. On day 3 (the rule-shift day), the dimension (odor or medium) signaling the reward was changed. If the initial association paired a specific odor with the food reward, then the rule-shift phase paired a certain digging medium with reward and the mice needed to learn this new rule to obtain a reward.

In the initial association and the rule-shift phases, the mice were considered to have learned the association between stimulus and reward if they made 10 consecutive correct choices. The phase ended when they met this criterion. When the mice made a correct choice on a trial, they were allowed to consume the food reward before the next trial. Between trials, mice were transferred from their home cage to a holding cage while new bowls were set up. After making an error on a trial, the mice were transferred to the holding cage for $1 \mathrm{~min}$ as punishment. In addition, in the rule-shift phase, two types of error were analyzed: perseverative errors, when a choice was consistent with the rule of the initial association phase, and random errors, when a choice was inconsistent with both the rules of the initial association and the rule-shift phases.

Experimental design and statistical analysis. All experiments reported in this study were designed to examine genotype-based effects between Foxp $1^{\text {cKO }}$ and littermate control mice. Effects on Foxp 1 protein levels in the brain (see Fig. $1 A-C$ ) were examined using adult ( $\geq 8$ weeks old) male mice ( 3 mice/genotype). Effects on activity in a novel cage activity test (see Fig. 2A,B) were tested using adult female and male mice (7-9 mice/ genotype). Effects on activity and anxiety in an open-field assay (see Fig. $2 C, D$ ) were examined in adult male and female mice ( 8 mice/genotype). Adult male mice (12-15 mice/genotype) were used to test genotypebased effects on ultrasonic vocalization (USV or song) production (see Fig. $3 A-F$ ). Genotype effects on nest building (see Fig. $3 G, H$ ) were as- 
A

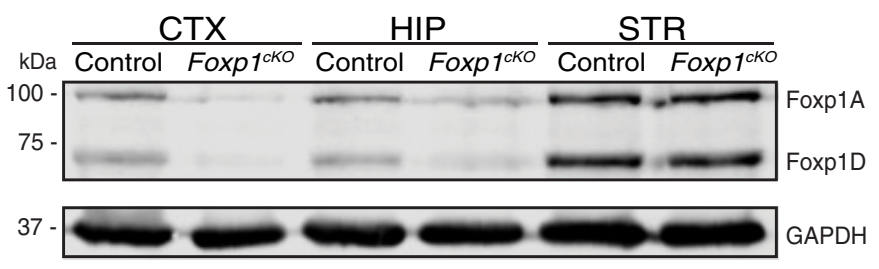

C
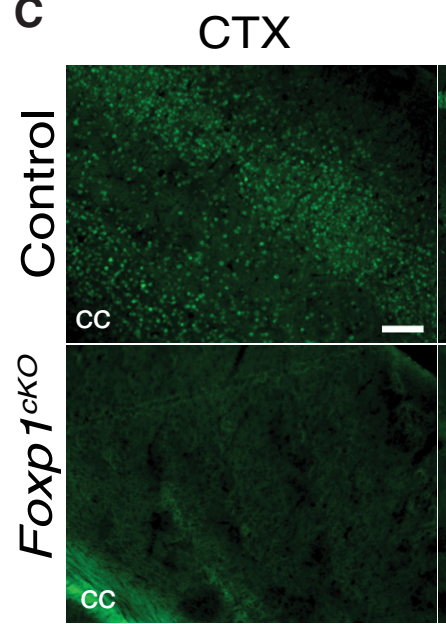

B

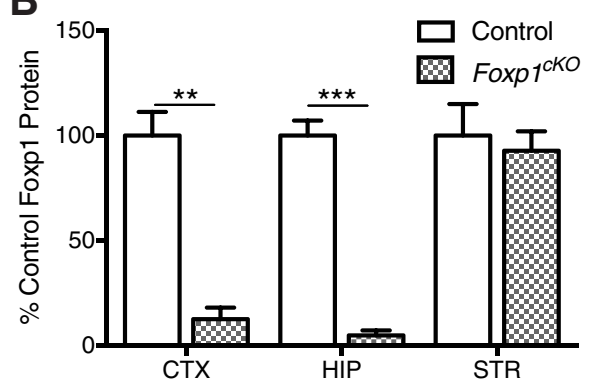

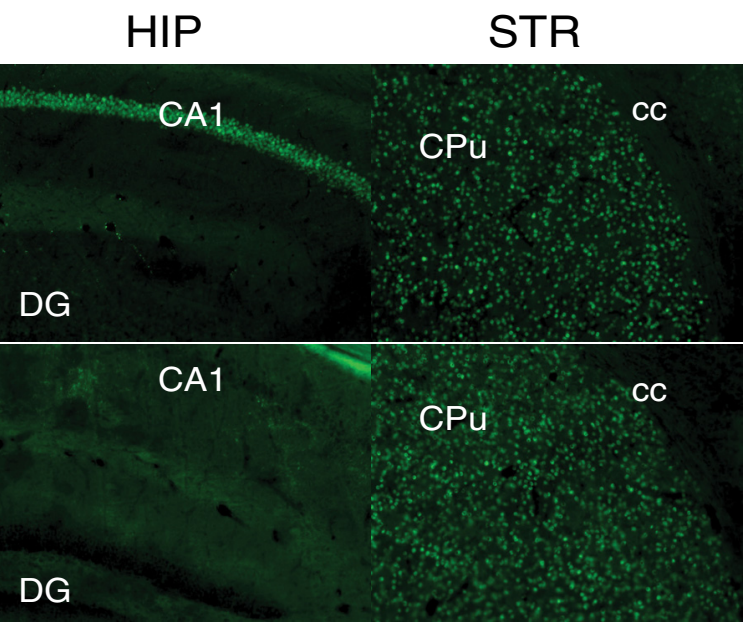

Figure 1. Generation of Foxp $1^{\mathrm{ck} 0}$ mice. $\boldsymbol{A}$, Representative immunoblot displaying reduced Foxp 1 protein levels in the CTX and HIP, but not the STR, of Foxp $1^{\mathrm{ck} 0}$ mice compared with littermate control mice. GAPDH was used as a loading control. B, Quantification of Foxp 1 expression in adult Foxp $1^{\text {ck0 }}$ mouse brains. Data are represented as means \pm SEM. $n=3$ control mice; $n=3$ Foxp ${ }^{\text {cK0 }}$ mice. ${ }^{* *} p=0.002 ;{ }^{* * *} p=0.0002$, Student's $t$ test, compared with control levels normalized to GAPDH. C, Representative immunohistochemistry images showing that Foxp1 protein (green) expression is ablated in the projection neurons of the CTX and the CA1/CA2 subfields of the HIP, but preserved in the STR of Foxp $1^{\text {cKO }}$ mice. cC, Corpus callosum; DG, dentate gyrus; CPu, caudate/putamen. Scale bars indicate $100 \mu \mathrm{m}$.

sessed in adult male and female mice (7-8 mice/genotype). Effects on sociability (see Fig. $3 I$ ) were determined using adult female and male mice (12-16 mice/genotype). Adult male mice (10-12 mice/genotype) were used to evaluate effects on performance in the Morris water maze (see Fig. $4 A-C$ ). Effects on performance in an alternating T-maze (see Fig. $4 D-F)$ were tested using adult male and female mice $(10$ mice/ genotype). Effects on performance in a fear-conditioning test (see Fig. $5 A, B)$ were determined using adult female and male mice (12-16 mice/ genotype). Adult male and female mice ( $9-10$ mice/genotype) were used to examine effects on performance in a set-shifting task (see Fig. $5 C, D$ ). Adult male mice (10 mice/genotype) were used to determine the effects of genotype of relative regional brain volumes (see Fig. $6 A, B$ ). Effects on hippocampal electrophysiological properties (see Fig. $8 A-C$ ) were determined using juvenile (6-7 weeks old) male mice (15-20 recordings/ genotype). Effects on gene expression via qPCR (see Figs. $7 F, 8 E$ ) were tested using adult male mice (3/genotype). Except as noted for genomic analyses, Student's $t$ tests (2-tailed, type 2) were performed for analyses of data in Figures $1 B ; 2, B-D ; 3, A-E, F, H$, and $I ; 4 C, D$, and $F ; 5 B ; 6 B ; 7 F$; and $8 B$ and $E$ and two-way ANOVAs (all with a Sidak's multiplecomparisons test) were performed for analyses of data in Figures $2 A ; 4, A$ and $E ; 4 A, C$, and $D$; and $5 C$. FDR was used for Figure $6 B$. $p$-values were calculated using Prism 7 software (GraphPad) and significance was assigned to values $\leq 0.05$. More detailed statistical information can be found in the Results section for each figure.

Gene Expression Omnibus (GEO) accession information. The National Center for Biotechnology Information GEO accession number for the RNA-seq data reported in this study is GSE97181.

\section{Results}

Foxp 1 is expressed within the pyramidal neurons of the neocortex and the CA1/CA2 hippocampal subfields (Ferland et al., 2003;
Hisaoka et al., 2010). However, the distinct ASD- and ID-related behavioral phenotypes governed by Foxp1 within these regions are undetermined. To examine the neocortical and hippocampal contributions of Foxp1 to ASD- and ID-relevant behaviors, we characterized Foxp1 conditional knock-out $\left(E m \times 1 . C r e^{+/-}\right.$; Foxp $1^{\text {flox/flox }}$ ) mice (hereafter called Foxp $1^{\text {cKO }}$ mice) compared with littermate control (Foxp $\left.1^{\text {flox/flox }}\right)$ mice.

There are four murine isoforms of Foxp1 and two of them (Foxp1A and Foxp1D) are highly expressed within the mouse brain (Wang et al., 2003; Araujo et al., 2015). Consistent with the forebrain expression pattern of Cre recombinase under the Emx 1 locus (Gorski et al., 2002), Foxp $1^{\mathrm{cKO}}$ mice displayed near total loss of Foxp1 protein isoforms $\mathrm{A}$ and $\mathrm{D}$ in the neocortex (CTX) and hippocampus (HIP; Fig. $1 A, B$; Student's $t$ test; CTX: $F_{(2,2)}=$ $4.21,{ }^{* *} p=0.002$; HIP: $\left.F_{(2,2)}=9.59^{* * *} p=0.0002\right)$. As a negative control, we demonstrated that Foxpl protein expression is preserved in the striatum (STR) of these animals (Fig. $1 A, B$; Student's $t$ test, $\left.F_{(2,2)}=2.67, p=0.7\right)$. Consistent with these results, we observed that Foxp1 expression is ablated in the projection neurons of the neocortex and the CA1/CA2 hippocampal subfields of Foxp $1^{\mathrm{cKO}}$ mice (Fig. 1C). Because neuroglia and interneurons do not express Foxp1 (Hisaoka et al., 2010; Precious et al., 2016), we believe that this decrease in protein levels is due to a loss of Foxp1 specifically in forebrain pyramidal neurons. Adult Foxp $1^{\mathrm{cKO}}$ mice are viable, superficially healthy, and exhibit no differences in body weight (Student's $t$ test, $F_{(14,14)}=2.45, p=$ $0.96, n=15$ mice/genotype). Therefore, these animals represent a model with which to examine the neocortical- and hippocampal- 
based contributions of Foxp 1 to ASD- and ID-relevant phenotypes.

Symptoms common between ASD and ID include hyperactivity and anxiety (van Steensel et al., 2011; Ageranioti-Bélanger et al., 2012; Leitner, 2014; de la TorreUbieta et al., 2016). Therefore, we first assessed the baseline activity of adult $(\geq 8$ weeks old) Foxp $1^{\mathrm{cKO}}$ mice. Foxp $1^{\mathrm{cKO}}$ mice exhibit sustained, increased activity over a $2 \mathrm{~h}$ period in a novel cage (Fig. $2 A$; two-way ANOVA; genotype effect: $F_{(1,336)}=163.6$, ${ }^{* * * *} p<0.0001$; time effect: $F_{(23,336)}=$ 22.44, $p<0.0001$; interaction effect: $F_{(23,336)}=2.2, p=0.001$; and Fig. $2 B$; Student's $t$ test, $\left.F_{(6,8)}=3.6,{ }^{* *} p=0.002\right)$. In addition, in an open-field assay, Foxp $1^{\text {cKO }}$ mice cover more distance (Fig. 2C; Student's $t$ test, $\left.F_{(7,7)}=2.62,{ }^{\star} p=0.02\right)$ and spend less time in the center of the arena, with a corresponding increase in time spent around the border of the arena (Fig. $2 D$; Student's $t$ test; time in center: $F_{(7,7)}=$ $2.79,{ }^{\star} p=0.02$; time in border: $F_{(7,7)}=$ $\left.2.7,{ }^{\star} p=0.02\right)$. Together, these findings suggest a phenotype of hyperactivity and increased anxiety in Foxp $1^{\mathrm{cKO}}$ mice.

Because decreased social communication is one of the core features of ASD (Fakhoury, 2015; Park et al., 2016; de la Torre-Ubieta et al., 2016), we examined both the social and communicative behaviors of Foxp $1^{\mathrm{cKO}}$ mice. The USV produced by adult male mice in response to the presence of female mice are a well characterized form of mouse communication (Holy and Guo, 2005; Portfors and Perkel, 2014). We therefore assayed the USVs, which are known as "songs," produced by adult male Foxp $1^{\text {cKO }}$ mice during courtship encounters with age-matched females. Foxp $1^{\text {cKO }}$ mice produce fewer numbers of songs (Fig. $3 A$; Student's $t$ test, $\left.F_{(14,12)}=1.12,{ }^{* *} p=0.002\right)$. In addition, the songs of Foxp $1^{\mathrm{cKO}}$ mice were shorter (Fig. $3 B$; Student's $t$ test, $\left.F_{(12,13)}=3.75,{ }^{\star} p=0.01\right)$, covered a smaller frequency range (Fig. $3 D$; Student's $t$ test, $F_{(12,13)}=1.94,{ }^{\star} p=0.02$ ), and were less complex, as revealed by both a reduction in the number of songs with frequency jumps (Fig. 3E; Student's $t$ test, $F_{(12,14)}=1.73$, ${ }^{*} p=0.02$ ) and an alteration in the average call slope (Fig. $3 F$; Student's $t$ test, $\left.F_{(13,12)}=1.72,{ }^{* *} p=0.0003\right)$. Notably, the mean frequency of Foxp $1^{\text {cKO }}$ songs was not altered (Fig. 3C; Student's $t$ test, $F_{(13,12)}=1.52, p=0.45$ ). (See the Materials and Methods section for details on call parameters.) We then tested nest building in Foxp $1^{\mathrm{cKO}}$ mice because it is an important behavior for communal animals such as rodents (Deacon, 2006; Silverman et al., 2010). Foxp $1^{\mathrm{cKO}}$ animals consistently produced low-quality nests and, in most cases, never interacted with the provided nesting material (Fig. $3 G, H$; Student's $t$ test, $F_{(6,7)}=2.29$, ${ }^{* * *} p<$ $0.0001)$. In a social interaction paradigm, Foxp $1^{\mathrm{cKO}}$ mice exhibited a social retreat phenotype, as indicated by their decreased time in the interaction zone (Fig. 3I; Student's $t$ test, $F_{(15,11)}=$ $\left.1.91,{ }^{* *} p<0.01\right)$ and their increased time in the corners of the testing arena (Fig. 3I, Student's $t$ test, $F_{(15,11)}=2.68,{ }^{* * *} p<$ $0.001)$. The increased preference for the corners of the sociability
Novel Cage Activity

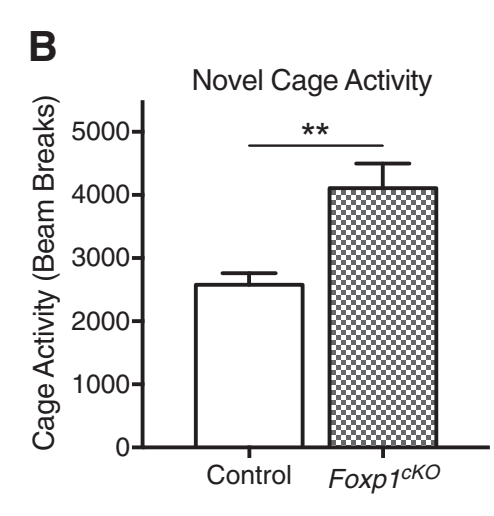

5 Minute Bins

D

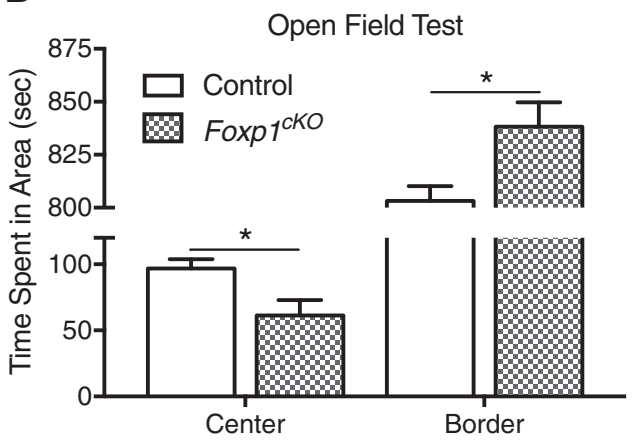

Figure 2. Foxp $1^{\mathrm{cK} 0}$ mice display hyperactivity and anxiety-like behaviors. $A, B$, Foxp ${ }^{\mathrm{cK} 0}$ mice are hyperactive, as indicated by their increased activity in a novel cage environment. $A, F o x p 1{ }^{\mathrm{ck} 0}$ mice display sustained, increased activity in a novel cage. Data are represented as means \pm SEM) $n=9$ control mice; $n=7$ Foxp $1^{\mathrm{CK} 0}$ mice. $p<0.0001$, two-way ANOVA, compared between meanses. $B$, As measured by their average activity over the course of $2 \mathrm{~h}$, Foxp ${ }^{\mathrm{Cl}}$ mice are hyperactive. Data are represented as C, Foxp $1^{\mathrm{cKO}}$ mice are hyperactive, as determined by their total distance moved in the open field test. Data are represented as means \pm SEM. $n=8$ control mice; $n=8$ Foxp ${ }^{{ }^{\mathrm{ck} 0}}$ mice. ${ }^{*} p=0.02$, Student's $t$ test, compared between genotypes. $D$, Foxp $1{ }^{\mathrm{ck} 0}$ mice are anxious, as determined by the amount of time they spend in the border of the open-field apparatus. Data are represented as means \pm SEM. $n=8$ control mice; $n=8$ Foxp $1^{\mathrm{cKO}}$ mice. ${ }^{*} p=0.02$, Student's $t$ test, compared between genotypes.

apparatus suggests that the decreased social interaction displayed by Foxp $1^{\mathrm{cKO}}$ mice was not simply due to hyperactivity. Together, our results indicate that neocortical and hippocampal loss of Foxp1 protein expression is sufficient to lead to ASD-relevant deficits in communication and sociability.

Because both ASD patients and patients with FOXP1 haploinsufficiency frequently present with ID (Le Fevre et al., 2013; Geschwind and State, 2015; Lozano et al., 2015; de la Torre-Ubieta et al., 2016), we next examined the learning and memory capabilities of Foxp $1^{\text {cKO }}$ mice. Over the course of $10 \mathrm{~d}$ of training in the Morris water maze, Foxp $1^{\mathrm{cKO}}$ mice never learn to find the submerged platform (Fig. 4A; two-way ANOVA; genotype effect: $F_{(1,200)}=199.6,{ }^{* * *} p<0.0001$; training day effect: $F_{(9,200)}=$ $6.98, p<0.0001$; interaction effect: $\left.F_{(9,200)}=3.25, p=0.001\right)$, indicating poor spatial learning (Vorhees and Williams, 2006). In addition, on a probe day $48 \mathrm{~h}$ after the last day of training, Foxp $1^{\mathrm{cKO}}$ mice made fewer numbers of platform crosses (Fig. $4 B$, C; Student's $t$ test, $\left.\mathrm{F}_{(11,9)}=2.78,{ }^{* *} p=0.002\right)$. This latter result was not unexpected, given that the Foxp $1^{\mathrm{cKO}}$ mice showed no demonstrable learning. These deficits in the Morris water maze were not due to problems in visual acuity because Foxp $1^{\mathrm{cKO}}$ mice were able to escape the maze just as quickly as control littermates on a visual probe day (Fig. 4D; Student's $t$ test, $F_{(11,9)}=3.88, p=0.34$ ). Moreover, these deficits were not due to changes in swim speeds because Foxp1 $1^{\mathrm{CKO}}$ mice showed no differences in their average 
A

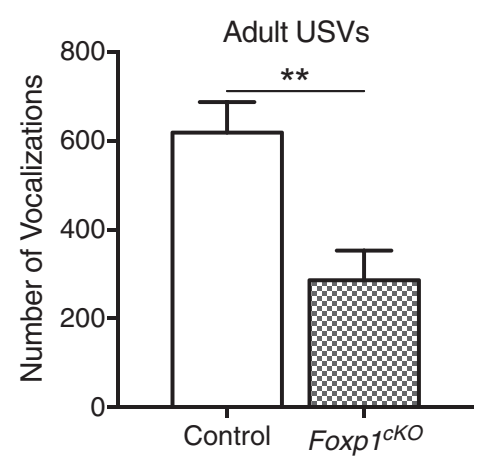

D

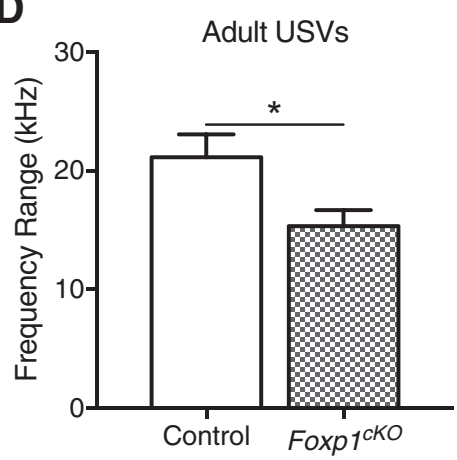

G

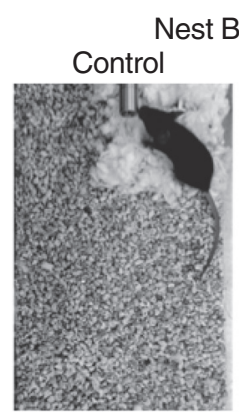

B

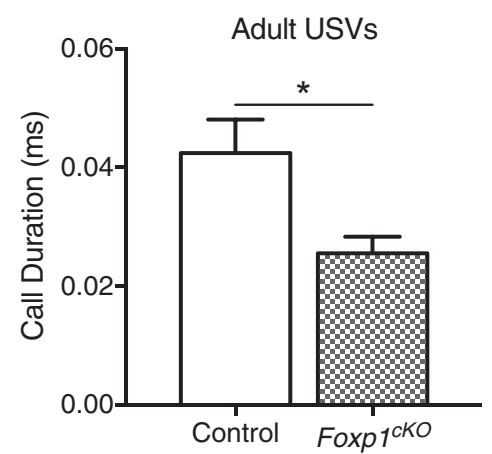

E

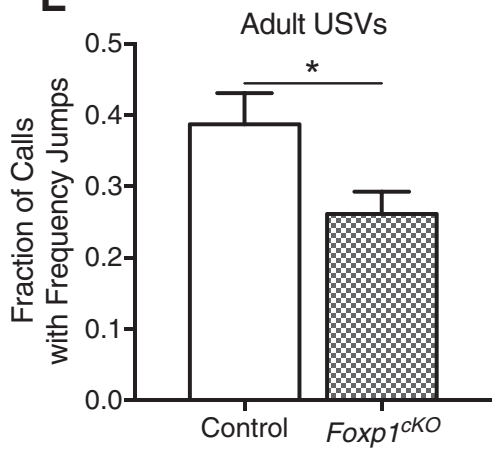

H

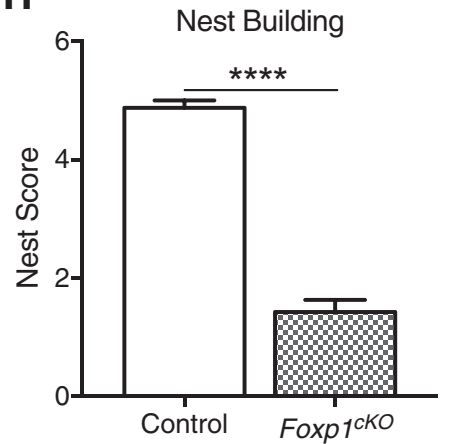

C

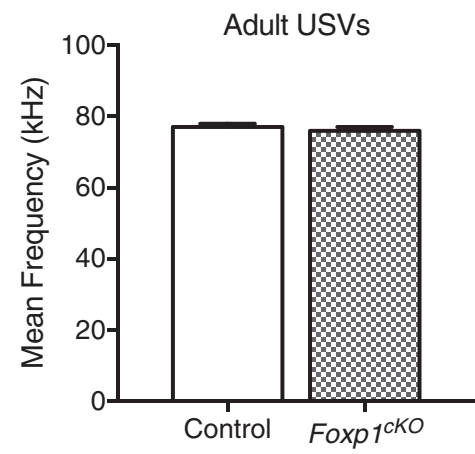

F

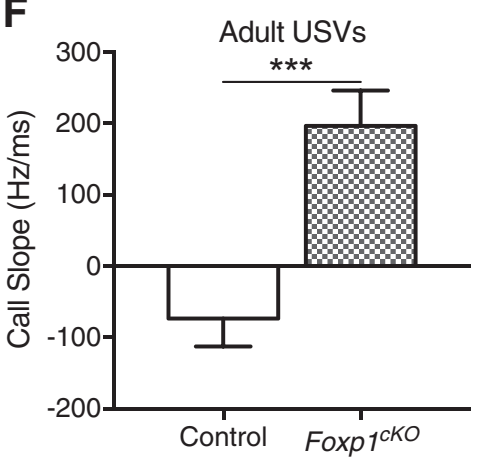

I

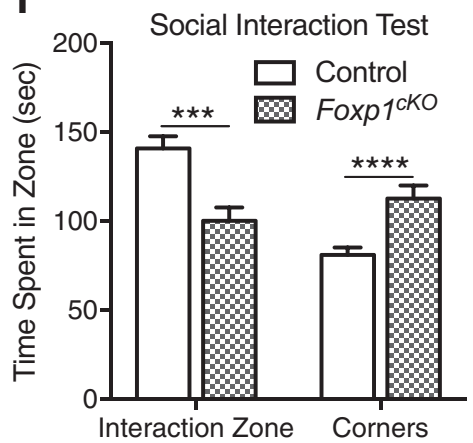

Figure 3. Impaired social communication in Foxp $7^{\mathrm{c} K 0}$ mice. $A$, Adult Foxp $1^{\mathrm{ck} 0}$ male mice produce fewer total numbers of USVs in a mating paradigm. Data are represented as means \pm SEM. $n=$ 13 control mice; $n=15$ Foxp $^{1 \mathrm{KK} 0}$ mice. ${ }^{* *} p=0.0019$, Student's $t$ test, compared between genotypes. $\boldsymbol{B}$, Foxp $7^{\mathrm{ck} 0}$ mice exhibit a significant reduction in their mean call duration. Data are represented as means \pm SEM. $n=13$ control mice; $n=14$ Foxp $1^{\mathrm{CK} 0}$ mice. ${ }^{*} p=0.011$, Student's $t$ test, compared between genotypes. $C$, Foxp ${ }^{\mathrm{ck} 0}$ mice show no differences in their mean call frequencies. Data are represented as means \pm SEM. $n=13$ control mice; $n=14$ Foxp $1^{{ }^{\mathrm{KK} 0}}$ mice. $p=0.45$, Student's t test, compared between genotypes. D, Adult Foxp ${ }^{\mathrm{cK} 0}$ male mice produce USVs with smaller frequency ranges. Data are represented as means \pm SEM. $n=13$ control mice; $n=14$ Foxp $1^{\mathrm{ck} 0}$ mice. ${ }^{*} p=0.019$, Student's $t$ test, compared between genotypes. $E$, Foxp ${ }^{\mathrm{ck} 0}$ mice produce a smaller fraction of USVs with frequency jumps. Data are represented as means \pm SEM. $n=13$ control mice; $n=15$ Foxp ${ }^{\mathrm{ck} 0}$ mice. $^{*} p=0.025$, Student's t test, compared between genotypes. $\boldsymbol{F}$, Foxp $1^{\mathrm{cK} 0}$ mice show a significant difference in the average slope of their USVs. Data are represented as means \pm SEM. $n=13$ control mice; $n=14$ Foxp ${ }^{\text {cKo } 0}$ mice. ${ }^{* * *} p=0.0003$, Student's $t$ test, compared between genotypes. $\boldsymbol{G}$, Representative photographs of the nests produced by littermate control and Foxp ${ }^{\mathrm{ck} 0}$ mice. $\boldsymbol{H}$, Foxp ${ }^{\mathrm{ck} 0}$ mice produce nests with low-quality scores. Data are represented as means \pm SEM. $n=8$ control mice; $n=7$ Foxp $1^{c \mathrm{k} 0}$ mice. ${ }^{* * *} p<0.0001$, Student's $t$ test, compared between genotypes. $I$, Foxp $1^{\mathrm{ck} 0}$ mice are less social than their littermate controls, as determined by the decreased time they spend interacting with a sex-matched conspecific (time in interaction zone). Data are represented as means \pm SEM. $n=16$ control mice; $n=12$ Foxp ${ }^{\text {cK0 }}$ mice. ${ }^{* *} p<0.01,{ }^{* * *} p<0.001$, Student's $t$ test, compared between genotypes.

swimming velocity during training (two-way ANOVA, genotype effect: $\left.F_{(1,120)}=3.35 p=0.07\right)$. In a T-maze, Foxp ${ }^{\text {cKO }}$ mice do no better than chance during the course of a 10-day training period (Fig. 4E; two-way ANOVA; genotype effect: $F_{(1,170)}=123.6$, ${ }_{* * * *} p<0.0001$; training day effect: $F_{(9,170)}=0.59, p=0.81$; interaction effect: $F_{(9,170)}=1.11, p=0.36$; and Fig. $4 F$; Student's $t$ test, $\left.F_{(8,9)}=1.3,{ }^{* * * x} p<0.0001\right)$, implying deficits in spatial working memory in these animals (Shoji et al., 2012). Learning in the Morris water maze and the T-maze both rely on hippocampal function (Vorhees and Williams, 2006; Shoji et al., 2012;
Yamamoto et al., 2014), so these results support altered hippocampal mechanisms in Foxp $1^{\text {cKO }}$ animals.

We next investigated whether the decreased performance of Foxp $1^{\mathrm{cKO}}$ mice in learning and memory tasks is due to impairments in broad cortical circuits or if it is restricted to hippocampal-based spatial memory. We first used cue/contextual fear conditioning because it involves hippocampal, neocortical, and amygdala-based circuits in associative learning and memory (Puzzo et al., 2014; Tovote et al., 2015). We observed no differences in the fear response of Foxp ${ }^{\mathrm{cKO}}$ mice as measured by their 
A

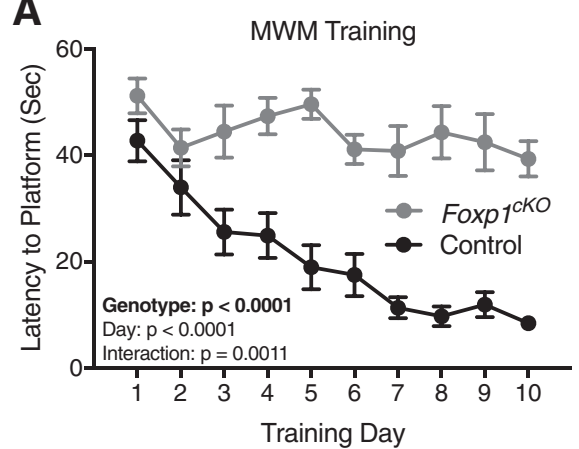

B

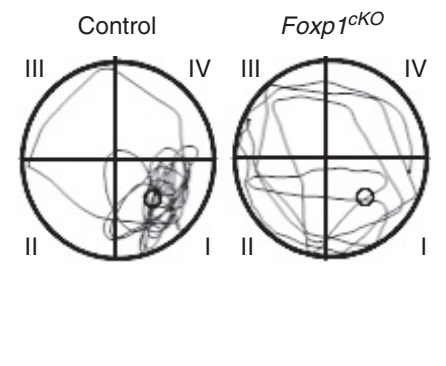

C

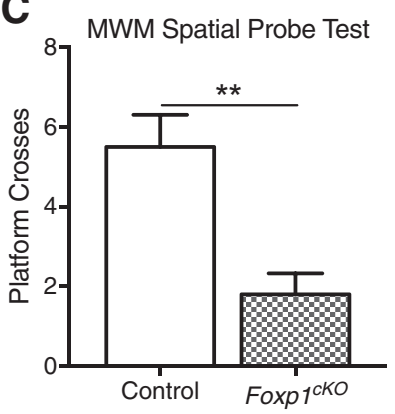

$\mathbf{F}$

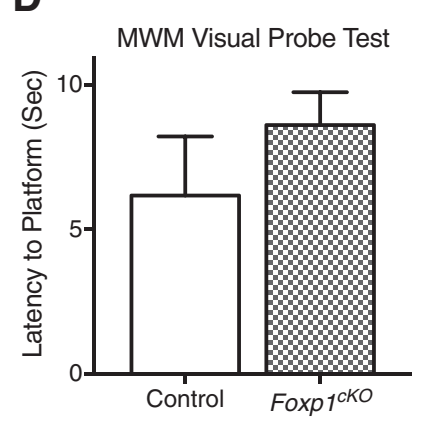

E

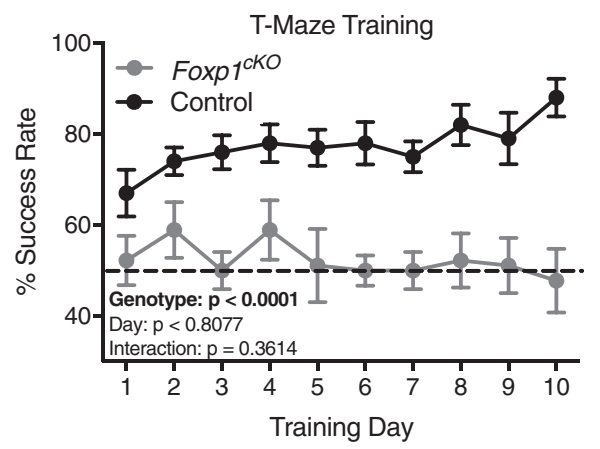

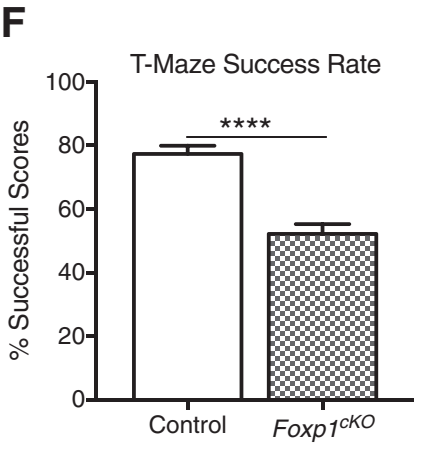

Figure 4. Foxp $7^{\mathrm{ck} 0}$ mice display impairments in spatial learning. $A$, Foxp $1^{\mathrm{ck} 0}$ mice display poor learning via their escape latency in the training phase of the Morris water maze (MWM). Data are represented as means \pm SEM. $n=12$ control mice; $n=10$ Foxp $1^{\mathrm{cK} 0}$ mice. $p<0.0001$, two-way ANOVA, compared between genotypes. $B, C$, Foxp $7^{\mathrm{ck} 0}$ show poor memory via the number of platform crosses that they make during the MWM spatial probe. $\boldsymbol{B}$, Representative trace of swimming paths taken by Foxp ${ }^{\mathrm{ck0}}$ and control littermate mice on a spatial probe day. Roman numerals designate different quadrants. The original location of the hidden platform is indicated by a circle in quadrant I. C, Quantification of the number of platform crosses made by Foxp $1{ }^{\mathrm{ckO}}$ and control mice on a spatial probe day. Data are represented as means \pm SEM. $n=12$ control mice; $n=10$ Foxp $1^{\mathrm{ck} 0}$ mice. ${ }^{* *} p=0.002$, Student's $t$ test, compared between genotypes. $\boldsymbol{D}$, Foxp $7^{\mathrm{ck} 0}$ mice display no difference in their ability to locate a raised platform during a visual probe day in the MWM. Data are represented as means \pm SEM. $n=12$ control mice; $n=10$ Foxp $1^{\mathrm{ck} 0}$ mice. $p=0.34$, Student's $t$ test, compared between genotypes. $E$, Foxp ${ }^{1 \mathrm{k} 0}$ mice demonstrate poor learning and memory, as measured by their percentage of successful trials during training in the T-maze. Dashed line represents success based on chance. Data are represented as means \pm SEM. $n=10$ control mice; $n=9$ Foxp $1^{\mathrm{ck} 0}$ mice. $p<0.0001$, two-way ANOVA, compared between genotypes. $F$, As measured by their average performance during training, Foxp $7^{\mathrm{cK} 0}$ mice display impaired learning in the T-maze. Data are represented as means \pm SEM. $n=10$ control mice; $n=10$ Foxp $1^{\mathrm{ck} 0}$ mice. ${ }^{* * * *} p<$ 0.0001 , Student's $t$ test, compared between genotypes. The main effects for genotype and postnatal day and their interactions are presented in $\boldsymbol{A}$ and $\boldsymbol{E}$.

performance in a cue-dependent fear-learning paradigm (Fig. $5 A$; two-way ANOVA; genotype effect: $F_{(1,52)}=1.23, p=0.27$; tone effect: $F_{(1,52)}=242, p<0.0001$; interaction effect: $F_{(1,52)}=$ $0.44, p=0.51)$. We also observed no differences in a contextdependent fear-learning paradigm (Fig. 5B; Student's $t$ test, $\left.F_{(11,15)}=2.63, p=0.12\right)$. Foxp ${ }^{{ }^{\mathrm{CKO}}}$ mice were able to hear the conditioned stimulus (the tone before the shock) because they demonstrated no differences in freezing when presented with the stimulus during training ( $p=0.77$, two-way ANOVA). Foxp $1^{\text {cKO }}$ mice were also able to perceive the unconditioned stimulus (the shock itself) just as well as their littermate controls because they showed no difference in the stimulus strengths needed to induce jumping, flinching, or vocalizing (Student's $t$ test; jumping: $F_{(11,15)}=1.44, p=0.53$; flinching: $F_{(11,15)}=1.51, p=0.40$; vocalizing: $\left.F_{(11,15)}=2.0, p=0.45\right)$. Given that contextual fear conditioning is heavily dependent on hippocampal function (Puzzo et al., 2014; Tovote et al., 2015), the intact context-dependent fear conditioning that we observed in Foxp $1^{\mathrm{cKO}}$ mice was surprising. This pointed to a specific deficit in complex hippocampal-based spatial tasks. To test this hypothesis, we examined the performance of Foxp $1^{\mathrm{cKO}}$ animals in a set-shifting paradigm, a complex task that is largely reliant on prefrontal neocortical function (Cho et al., 2015; Heisler et al., 2015). We saw no differences in the behavior of Foxp ${ }^{\text {cKO }}$ mice compared with controls during the set-shifting task, as measured by the number of trials needed to reach criterion for training or the number of errors made during testing (Fig. $5 C$; two-way ANOVA; genotype effect: $F_{(1,9)}=0.219, p=0.65$; test phase effect: $F_{(1,9)}=14.74, p=0.004$; interaction effect: $F_{(1,9)}=$ 1.05, $p=0.33$; and Fig. 5D; two-way ANOVA; genotype effect: $F_{(1,18)}=0.65, p=0.43$; error type effect: $F_{(1,18)}=33.51, p<$ 0.0001 ; interaction effect: $\left.F_{(1,18)}=0.11, p=0.74\right)$. Together, these results indicate that the learning and memory deficits seen in Foxp $1^{\mathrm{cKO}}$ mice were restricted to complex, spatial, hippocampal-based processes.

The behavioral deficits that we observed in Foxp $1^{\mathrm{cKO}}$ mice are associated with many molecular mechanisms in the hippocampus (Lynch, 2004; Kumar, 2011). To determine the processes governing the behavioral phenotypes in Foxp $1^{\mathrm{cKO}}$ mice, we ascertained transcriptional changes due to Foxp1 loss by carrying out RNA-seq on tissue samples from the neocortex and hippocampus of both Foxp $1^{\mathrm{cKO}}$ mice and littermate controls. DEGs were identified by applying an adjusted $p$-value of $\leq 0.005$ and an absolute log fold change of $\geq 0.3$ (see "GEO accession information" section in Materials and Methods). By clustering the same number of top DEGs (based on fold change) in both the neocortex and hippocampus, we found transcriptional signatures (gene clusters) that differentiated the two brain regions by genotype (Fig. $6 A$ ). In addition, these upregulated and downregulated gene clusters are enriched for specific GO categories (https://toppgene.cchmc.org; Fig. 6A and Fig. 6-1, available at https://doi.org/10.1523/JNEUROSCI. 1005-17.2017.f6-1). For the hippocampus, these GO categories include terms such as reduced LTP, abnormal synaptic transmis- 
A

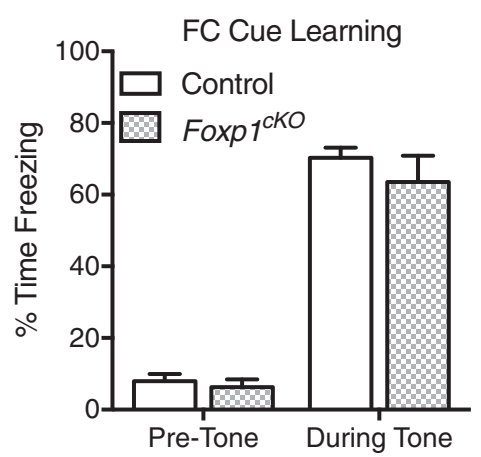

C

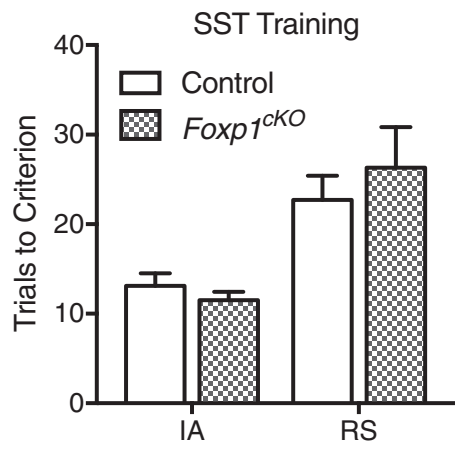

B

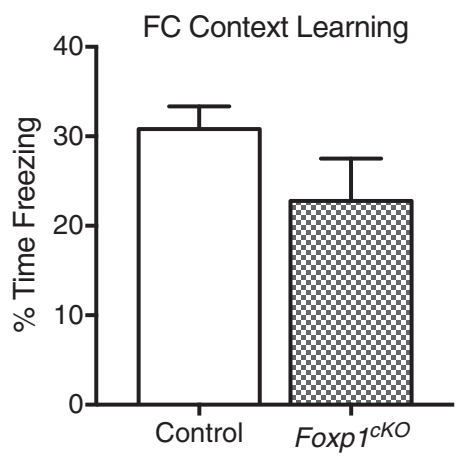

D

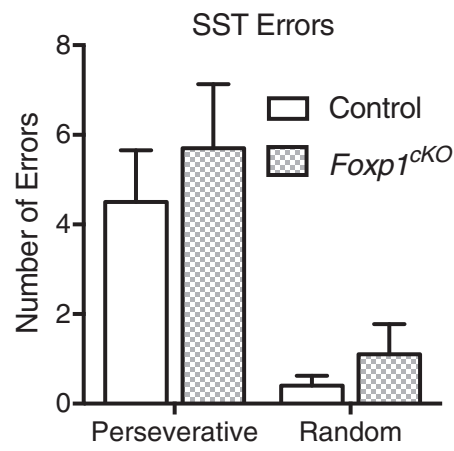

Figure 5. Foxp $1^{\mathrm{CK} 0}$ mice do not display deficits in generalized learning and memory. $\boldsymbol{A}, \boldsymbol{B}$, Foxp $1^{\mathrm{ck} 0}$ mice show no deficiencies in associative fear-memory tasks, as displayed by their performance in both the cue-dependent $(\boldsymbol{A})$ and context-dependent $(\boldsymbol{B})$ portions of a fear conditioning (FC) paradigm. Data are represented as means \pm SEM. $n=16$ control mice; $n=12$ Foxp $1^{\mathrm{cKO}}$ mice. $p=0.27$, two-way ANOVA compared between genotypes $(\boldsymbol{A}), p=0.12$, Student's $t$ test compared between genotypes $(\boldsymbol{B})$. $\boldsymbol{C}, \boldsymbol{D}$, Foxp ${ }^{\text {ck0 }}$ show no deficits in cognitive flexibility, as measured by the number of trials that they needed to reach criterion during both the initial association (IA) or the rule-shift (RS) portion of training for the set-shifting task (SST) (C) or the number of perseverative (Pers) or random (Rand) errors that they made in the RS portion of the SST (D). Data are represented as means \pm SEM. $n=10$ control; $n=9$ Foxp ${ }^{\text {cK0 }}$ mice. $p=0.65(\boldsymbol{C})$ and $p=0.43(\boldsymbol{D})$, two-way ANOVA, compared between genotypes.

sion, and abnormal learning/memory/conditioning (Fig. 6A; Benjamini-Hochberg-corrected $p$-value, $q$-value; reduced LTP, $q=5.09 \times 10^{-4}$; abnormal synaptic transmission, $q=5.64 \times 10^{-4}$, abnormal learning/memory/conditioning, $\left.q=8.57 \times 10^{-4}\right)$.

To characterize the relevance of Foxp $1^{\mathrm{cKO}}$ hippocampal and neocortical DEGs with regard to ASD pathophysiology, we overlapped these lists with those genes included on the Simons Foundation Autism Research Initiative (SFARI) website (843 genes; https://sfari.org/resources/sfari-gene). The SFARI gene list represents ASD risk genes that have been curated manually from the scientific literature. We found that both the neocortical and hippocampal Foxp $1^{\mathrm{cKO}}$ DEGs overlapped significantly with the ASD-SFARI genes (Fig. $6 B$; hypergeometric test; overlap between Foxp $1^{\text {cKO }}$ CTX and SFARI-ASD genes, $p=2.8 \times 10^{-7}$; overlap between Foxp $1^{\text {cKO }}$ HIP and SFARI-ASD genes, $p=3.8 \times 10^{-9}$ ). When we excluded ASD-SFARI genes from categories 5 and 6 (hypothesized and not supported, respectively) from this analysis, we obtained a similar result (hypergeometric test; 17 genes $(p=0.003)$ for Foxp $1^{\mathrm{cKO}}$ hippocampal DEGs and 49 genes $(p=$ 0.0002 ) for Foxp $1^{\text {cKO }}$ neocortical DEGs). Finally, accounting for directional consistency, we found a significant overlap between the Foxp $1^{\mathrm{cKO}}$ neocortical and hippocampal DEG datasets (Fig. $6 B$; hypergeometric test, overlap between Foxp $1^{\text {cKO }}$ HIP and Foxp $1^{\text {cKO }}$ CTX genes, $\left.p=4.7 \times 10^{-31}\right)$. The genes included in this directional overlap are enriched for GO categories such as potassium channel activity (Benjamini-Hochberg-corrected $p$-value, $q=3.3 \times 10^{-3}$ ) and calcium ion transmembrane trans- porter activity (Benjamini-Hochbergcorrected $p$-value, $q=2.6 \times 10^{-2}$ ). Combined with our previous report (Araujo et al., 2015), these data suggest that, although Foxp1 regulates distinct targets within different neuronal populations, it has an overall role in regulating the expression of ASD risk genes and ion receptor genes throughout the brain.

Next, to understand the role of Foxp 1 specifically within the hippocampus, we compared the transcriptional targets in the hippocampus of the Foxp $1^{\text {cKO }}$ mice with DEGs we identified previously in a whole-body heterozygous Foxp1 knockout $\left(F o x p 1^{+/-}\right)$mouse (Araujo et al., 2015). We were unable to compare neocortical data because there were no DEGs in the neocortex of the heterozygous Foxp1 mice (Araujo et al., 2015). When we applied the same DEG cutoffs to these two datasets, we found a significant overlap of directionally consistent hippocampal target genes in these two Foxp1 mouse models (Fig. 6C; hypergeometric test, $p=$ $\left.1.8 \times 10^{-22}\right)$. This overlap represented $\sim 20 \%$ of the Foxp1 $1^{\text {cKO }}$ DEGs, but only $\sim 9 \%$ of the Foxp1 $1^{+/-}$DEGs. That a relatively small proportion of Foxp $1^{+/-}$hippocampal DEGs overlapped with the DEGs in the Foxp $1^{\text {cKO }}$ mouse hippocampus is an important finding because the only major behavioral phenotype seen in Foxp $1^{+/-}$mice was an alteration in USV production (Araujo et al., 2015). Furthermore, we did not observe a learning and memory deficit in the Foxp $1^{+/-}$mice using a novel object recognition task (data not shown). Together, these results indicate that complete and partial loss of Foxp1 produce unique alterations in signaling pathways in the hippocampus. Moreover, these data suggest that the nonoverlapping genes in the Foxp1 ${ }^{\text {cKO }}$ hippocampus are likely important for the observed learning and memory deficits seen in Foxp $1^{\mathrm{cKO}}$ mice.

Next, we sought to determine the extent to which Foxp $1^{\text {cKO }}$ hippocampal DEGs affect signaling processes involved in hippocampal neuron identity. Specifically, we wanted to assess whether loss of Foxp 1 perturbs the expression of genes specific to CA1 pyramidal neurons. To accomplish this, we overlapped the Foxp $1^{\text {cKO }}$ hippocampal DEGs with CA1-specific genes identified by single-cell sequencing of the mouse CA1 (Zeisel et al., 2015). We found a significant overlap between these two gene expression datasets (Fig. $6 D$; hypergeometric test, $p=1.7 \times 10^{-15}$; Fig. 6-2, available at https://doi.org/10.1523/JNEUROSCI.1005-17. 2017.f6-2). The relatively small size of this overlap ( $\sim 15 \%$ of the Foxp $1^{\text {cKO }}$ hippocampal DEGs) was most likely due to the fact that our RNA-seq data captured direct and indirect (as well as cellautonomous and non-cell-autonomous) gene expression changes due to loss of Foxp1 in both CA1 and CA2 neurons throughout the entirety of the hippocampus.

We then used WGCNA to further prioritize Foxp $1^{\mathrm{cKO}}$ hippocampal DEGs with respect to ASD and ID (Langfelder and Horvath, 2008). WGCNA allows for the identification of networks (or modules) of genes with high coexpression. Three 

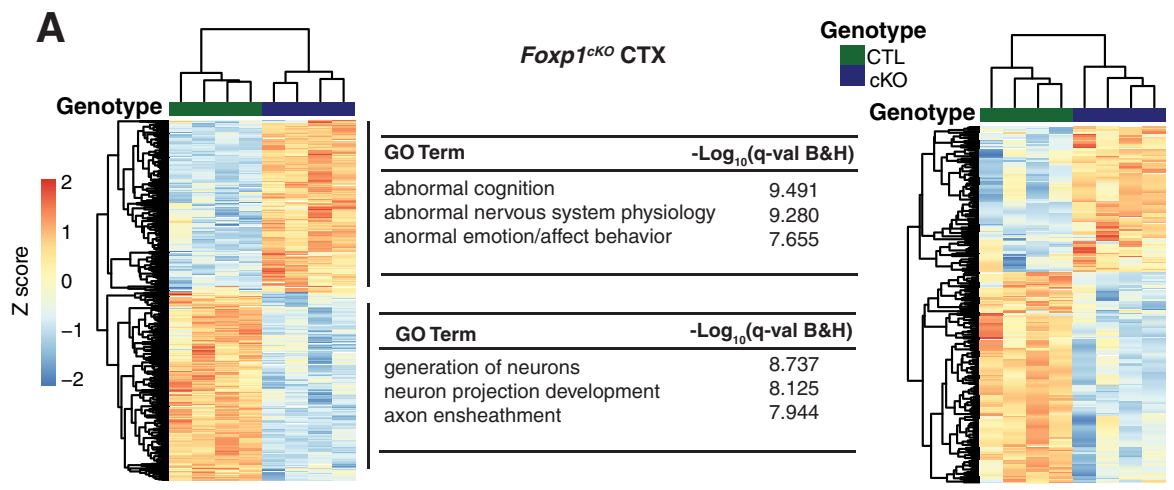

Foxp ${ }^{c k o}$ HIP

B

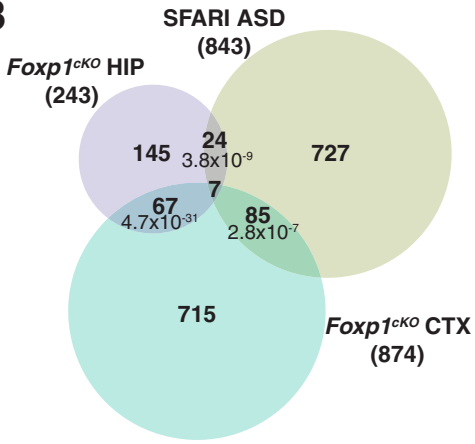

E

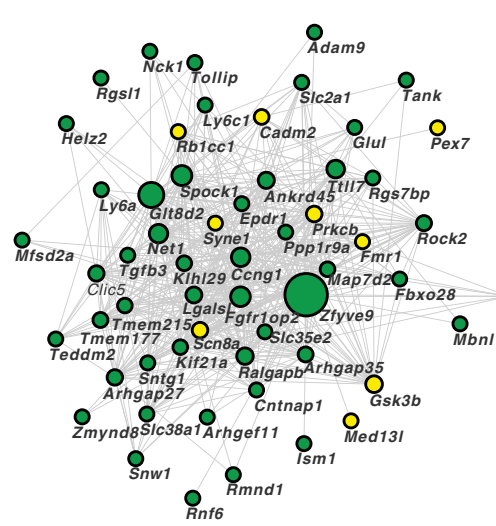

H

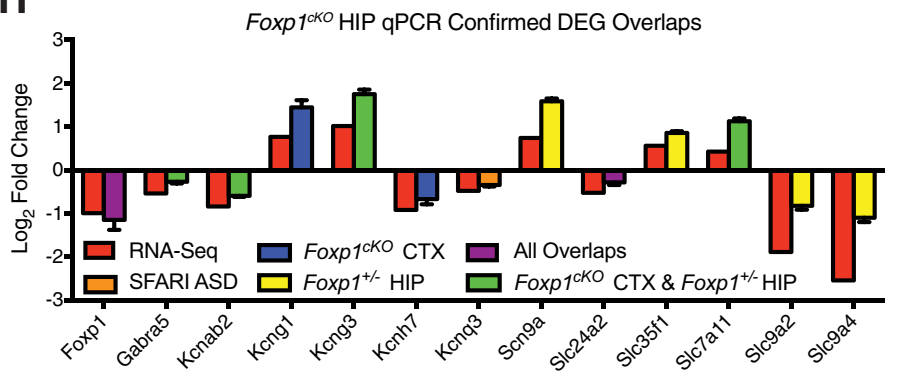

C

F \&ibp

\&op4

Qsir Fam $132 a^{2}$

Dync1i2 Grasp $_{\text {Hac9 }}^{\text {Mmab }} 8_{\text {dah } 1}$

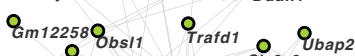

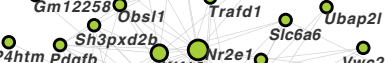

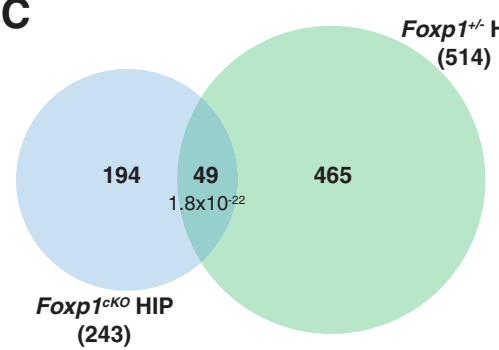

\begin{tabular}{|lc}
\hline GO Term & $\operatorname{-og}_{10}(\mathbf{q}-\mathrm{val} \mathbf{B} \& \mathrm{H})$ \\
\hline neurological system process & 3.456 \\
neurogenesis & 3.239 \\
neuron differentiation & 3.239 \\
\hline & \\
\hline & $\operatorname{-Log}_{10}(\mathbf{q}-\mathbf{v a l ~ B \& H})$ \\
\hline GO Term & 3.293 \\
reduced long-term potentiation & 3.249 \\
abnormal synaptic transmission & 3.067 \\
abnormal learning/memory/conditioning & \\
\hline
\end{tabular}

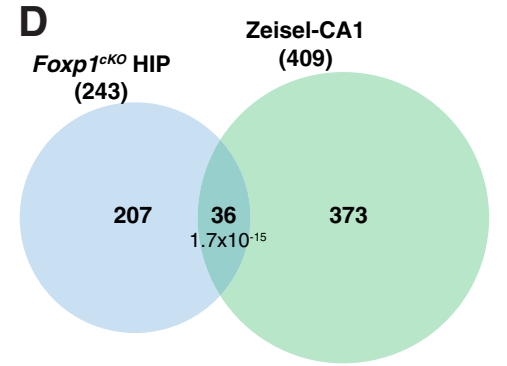

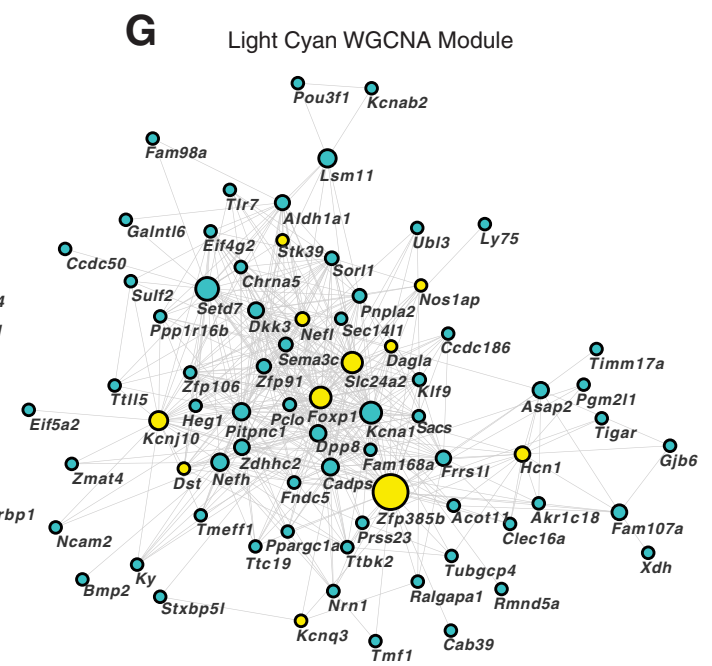

1+/ HIP

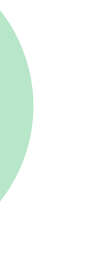

( 
modules were genotype specific (Fig. $6 E-G$ ). The "dark green" module was hippocampus specific (Fig. 6E) and contained several ASD-SFARI genes such as Cadm2, Prkcb, Scn8a, and Syne1. The dark green module also contained Fmr1, which when disrupted in humans leads to Fragile X syndrome, which frequently includes the presentation of ID (Hernandez et al., 2009). In addition, both the "green yellow" and "light cyan" modules also included a number of ASD-SFARI genes (Fig. $6 F, G$ ). The light cyan module not only included Foxp1, but also several ASDrelated genes encoding ion channels such as Kcnj10, Kcnq3, and Slc24a2 (Fig. 6G). Finally, a number of Foxp $1^{\mathrm{cKO}}$ hippocampal DEGs that overlapped with each of the relevant gene lists discussed above (SFARI-ASD genes and/or Foxp $1^{\mathrm{cKO}}$ neocortical DEGs and/or Foxp1 $1^{+/-}$hippocampal DEGs) were chosen at random and confirmed in independent Foxp $1^{\mathrm{cKO}}$ hippocampal samples via qPCR (Fig. $6 H$; Student's $t$ test, $p<0.05$ for all genes). In summary, these genomic data identify transcriptional programs downstream of Foxp1 that may drive the regulation of hippocampal function.

The genomic data indicated a role for Foxp1 in the regulation of both neocortical and hippocampal development (Fig. 6A,D). To assess neuroanatomical alterations due to forebrain Foxp 1 loss that could explain the observed phenotypes, we analyzed the brains of Foxp1 $1^{\text {cKO }}$ mice via MRI, which has been used on other ASD mouse models (Ellegood et al., 2015). We chose to focus our analyses on relative regional volumes (normalized to total volumes) because there was a significant decrease in the overall volume of Foxp $1^{\text {cKO }}$ mouse brains $(-12 \%, p<0.0001$, Student's $t$ test and FDR $<1 \%$ ). In summary, we found reductions and increases in the relative volumes of numerous brain regions in Foxp $1^{\mathrm{cKO}}$ mice (Fig. $7 A, B ; p<0.05$, Student's $t$ test, and FDR $<0.05$ for all regions; Fig. 7-1, available at https://doi.org/ 10.1523/JNEUROSCI.1005-17.2017.f7-1). Brain regions with decreased relative volumes constituted neuronal populations expressing $E m x 1$ (including many neocortical areas) or white matter tracts originating from populations expressing Emxl (Fig. $7 A, B$ and Fig. 7-1, available at https://doi.org/10.1523/JNEUROSCI. 1005-17. 2017.f7-1). Interestingly, the most affected region (in terms of percentage decrease) was the hippocampus (Fig. 7B). Moreover, hippocampal subfields and parahippocampal regions such as the dentate gyrus, stratum granulosum, and the pre-para subiculum were also significantly reduced in volume (Fig. 7 A, B and Fig. 7-1, available at https://doi.org/10.1523/JNEUROSCI. 1005-17.2017. f7-1). Brain regions with increased relative volumes mostly constituted cerebellar nuclei, cerebellar white matter tracts, and subcortical nuclei (Fig. 7A and Fig. 7-1, available at https://doi. org/10.1523/JNEUROSCI.1005-17.2017.f7-1). Taken as a whole, these data demonstrate that loss of Foxp1 expression in the forebrain leads to alterations in regional volumes throughout the brain, with hippocampal structures being affected drastically.

The significant decrease in hippocampal volumes exhibited by Foxp $1^{\mathrm{cKO}}$ mice suggested alterations in the functional properties of this region (Fig. $7 A, B$ ). In addition, plasticity in general and

\footnotetext{
(Figure legend continued.)in the hippocampus-specific dark green module $(\boldsymbol{E})$, the green yellow module $(\boldsymbol{F})$, and the light cyan module $(\boldsymbol{G})$. ASD-SFARI genes are highlighted in yellow. $\boldsymbol{H}$, Confirmation of salient gene targets in independent $F$ oxp $7^{\mathrm{C} 0}$ hippocampal samples using qPCR. Red bars indicate RNA-seq-based $\log _{2}$-fold changes in expression. Colored bars represent the category of gene (SFARI-ASD and/or Foxp ${ }^{\mathrm{cK} 0}$ neocortex and/or Foxp $1^{+/-}$hippocampus) that these Foxp $1^{\mathrm{cKO}}$ hippocampal DEGs overlap with. Data are represented as means \pm SEM. $n=3$ control mice; $n=3$ Foxp $1^{\text {ck0 }}$ mice. All qPCR values are significant at $p<0.05$ (Student's $t$ test, compared with control levels, normalized to $\beta$-actin).
}

LTP in particular were GO categories enriched in the Foxp $1^{\text {cKO }}$ HIP DEGs (Fig. 6A). LTP is a well studied process by which excitatory synapses are strengthened in response to neuronal stimulation (Lynch, 2004; Kumar, 2011). Hippocampal LTP mediated by projections from CA3 pyramidal neurons to CA1 pyramidal neurons (Schaffer collateral projections) is thought to underlie the encoding of spatial memory (Lynch, 2004; Kumar, 2011). Therefore, we chose to examine hippocampal LTP in Foxp $1^{\mathrm{cKO}}$ mice. Given that Foxp 1 expression in the hippocampus is restricted to CA1/2 pyramidal neurons (Ferland et al., 2003), we recorded LTP in area CA1 in response to Schaffer collateral stimulation in Foxp $1^{\mathrm{cKO}}$ mice. Although the initial magnitude of CA1 LTP was normal in Foxp $1^{\mathrm{cKO}}$ mice (Fig. $8 A$, arrows), the mean magnitude of LTP during the last 10 min of stimulation was reduced significantly (Fig. $8 A, B$; Student's $t$ test, $F_{(19,14)}=2.16$, ${ }^{* * * *} p<0.0001$ ), indicative of impaired plasticity maintenance. This result was not due to differential baseline synaptic transmission in the Foxp1 ${ }^{\mathrm{cKO}}$ mice because we found no difference in the fEPSP slope relative to current stimulation intensity (Fig. $8 C$; two-way ANOVA; genotype effect: $F_{(1,236)}=0.23, p=0.63$; time effect: $F_{(7,236)}=11.97, p<0.0001$; interaction effect: $F_{(7,236)}=$ $0.04, p>0.99)$. To characterize the Foxp $1^{\mathrm{cKO}}$ hippocampal RNAseq data with regard to genes involved in LTP maintenance, we overlapped our gene list with a dataset generated from microarrays performed on hippocampi $5 \mathrm{~h}$ after undergoing LTPinducing high-frequency stimulation (Ryan et al., 2012). These two datasets overlapped significantly (Fig. $8 D$; hypergeometric test, $p=2.32 \times 10^{-4}$ ). We then tested all 12 of the overlapping genes (which included Foxp1) via qPCR and were able to confirm differential expression for 9 of them in independent Foxp $1^{\text {cKO }}$ hippocampal samples (Fig. $8 E$; Student's $t$ test, $p<0.05$ for all genes except Ccnd1, Dusp5, and Sorcs3). Of the 12 genes overlapping between the LTP maintenance dataset and the Foxp $1^{\text {cKO }}$ hippocampus dataset, seven (Ccnd1, Dsp, Gnb4, Grin3a, Rasd1, Runx1t1, and Sorcs3) are not included in the Foxp1 $1^{+/-}$hippocampus dataset (Araujo et al., 2015). These seven genes therefore represent mechanisms that are uniquely disrupted in the Foxp $1^{\text {cKO }}$ hippocampus and could explain the physiological and behavioral phenotypes displayed by Foxp $1^{\mathrm{cKO}}$ mice. Indeed, several of these genes (Rasd1, Gnb4, and Grin3a) have been implicated directly in hippocampal-based learning and memory (de Quervain and Papassotiropoulos, 2006; Vilches et al., 2014; Carlson et al., 2016). These data suggest that control of genes involved in hippocampal LTP maintenance is disrupted in Foxp $1^{\mathrm{cKO}}$ mice and that this may contribute to their learning and memory deficits.

\section{Discussion}

Elucidating molecular mechanisms important for learning and memory is an ambitious undertaking, especially in terms of connecting these mechanisms to disorders such as ASD and ID. Numerous genes have been linked to an increased risk for both of these disorders and this suggests common mechanisms between them (Santini and Klann, 2014; Plummer et al., 2016). However, only a few of these genes have been categorized as high-confidence risk genes (Iossifov et al., 2014; Sanders et al., 2015; Mullins et al., 2016; Vissers et al., 2016; de la Torre-Ubieta et al., 2016; Stessman et al., 2017). FOXP1 is among this list of highconfidence ASD and ID risk genes (Iossifov et al., 2014; Sanders et al., 2015; Vissers et al., 2016; Stessman et al., 2017), yet relatively little is known about the function of FOXP1 in the brain. Previously, we demonstrated that an ASD- and ID-patient-relevant haploinsufficient Foxp1 mouse model exhibits vocalization deficits with alterations in striatal function and gene expression 
A Foxp $1^{\mathrm{cko}}$ vs. Control

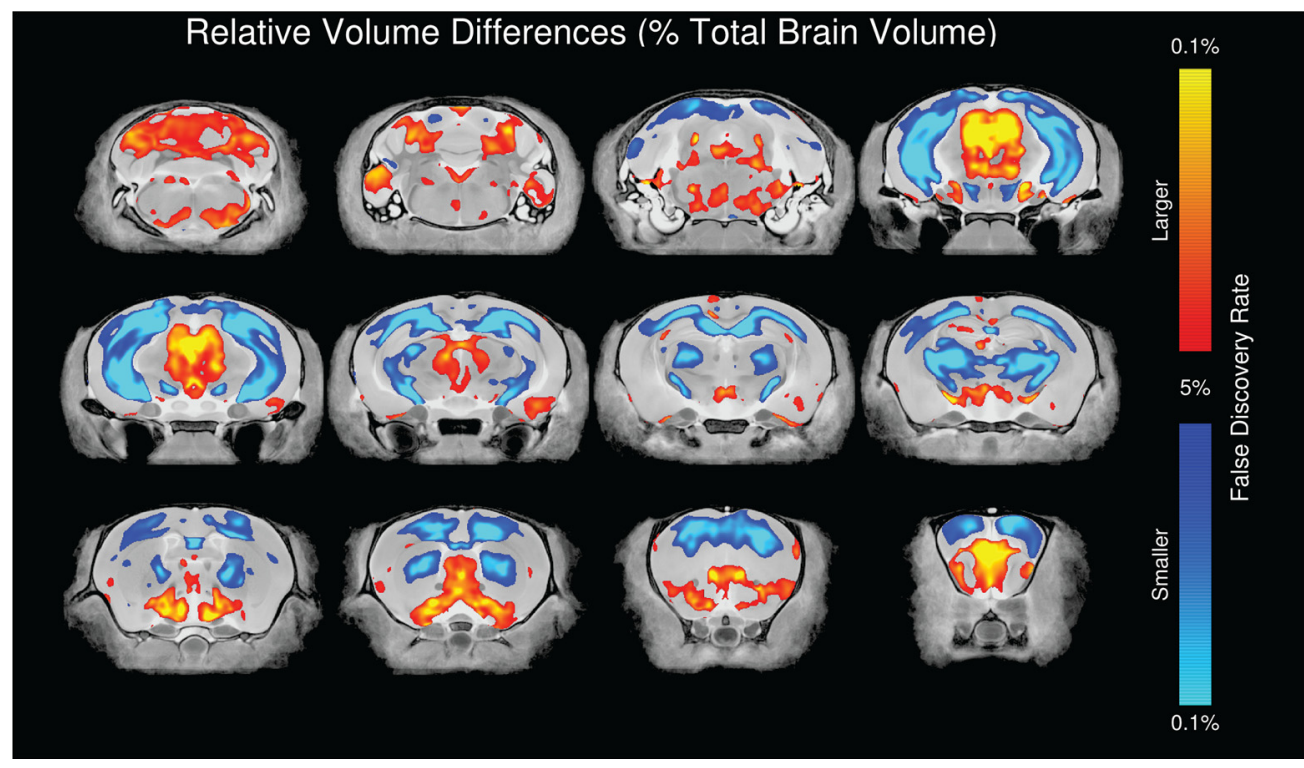

B

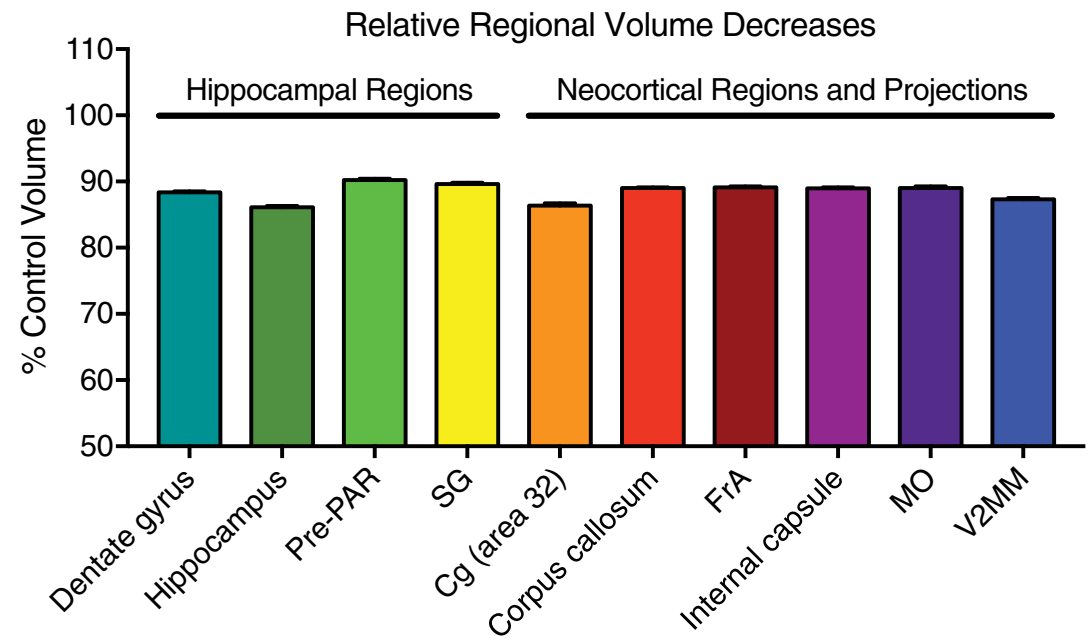

Figure 7. Altered regional brain volumes in Foxp $7^{\mathrm{c} K 0}$ mice. $\boldsymbol{A}$, Fly-through of representative coronal slices of the Foxp ${ }^{\mathrm{ck} 0}$ brain highlighting average relative differences in regions with larger (red) or smaller (blue) volumes. $\boldsymbol{B}$, Representation of the average relative volume decreases in several of the most significantly (in terms of percentage decreases from control $100 \%$ levels) affected hippocampal and neocortical areas in the Foxp $7^{\mathrm{cK} 0}$ mouse brain. Dashed line represents control levels. Data are represented as means \pm SEM. All values are significant at $p<0.05$, Student's $t$ test, and FDR $<0.05$. Cg, Cingulate cortex; FrA, frontal association cortex; M0, medial orbital cortex; Pre-PAR, pre-para subiculum; V2MM, secondary visual cortex mediomedial area. The top 20 increases and decreases in relative regional brain volumes (in terms of percentage difference from control volumes) are in Figure 7-1 (available at https://doi.org/10.1523/JNEUROSCl.1005-17.2017.f7-1).

(Araujo et al., 2015). In addition, a mouse model with complete loss of Foxp1 in the brain demonstrates a number of behavioral deficits and functional alterations in several brain regions (Bacon et al., 2015). Therefore, these previously published data do not address the requirement for Foxpl in specific brain regions and how such a requirement might be important for specific ASD- and ID-relevant phenotypes.

To investigate the functional role of Foxp1 in a brain-regionspecific manner, we generated Foxp $1^{\mathrm{cKO}}$ mice with complete loss of Foxp1 in the hippocampus and neocortex (Fig. 1A,B). We observe a number of striking behavioral deficits in these mice, most notably altered social interactions (Fig. 3I) and an almost total absence of spatial learning (Fig. $4 A-F$ ). Because the neural circuits for social behaviors are not understood fully and because the hippocampus has been studied in depth for its relationship to learning and memory, we chose to focus on the potential role of
Foxp1 in hippocampal-based functions in Foxp $1^{\mathrm{cKO}}$ mice. Importantly, the majority of documented patients with ASD-causing mutations in FOXP1 also have a diagnosis of ID (Le Fevre et al., 2013; Lozano et al., 2015; Vissers et al., 2016), making a mechanistic study of Foxp1 function in the hippocampus disease relevant.

Foxp $1^{\mathrm{cKO}}$ mice possess deficits in spatial learning because they perform poorly in both the alternating T-maze and the Morris water maze (Fig. 4A-F). Conversely, Foxp $1^{\mathrm{cKO}}$ mice have intact learning in contextual fear conditioning (Fig. $5 A, B$ ). Such results are seemingly in conflict with one another. However, when performed before testing, lesions of the hippocampus impair learning in the Morris water maze but preserve contextual fear conditioning in mice (Cho et al., 1999). Indeed, other mouse models of neuropsychiatric disorders have also shown that these two processes can be dissociated (Kubota et al., 2001; Huynh et al., 2009). Another explanation could be that hippocampal func- 
A

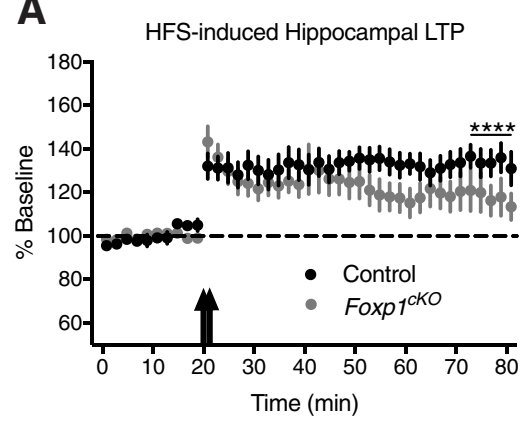

D

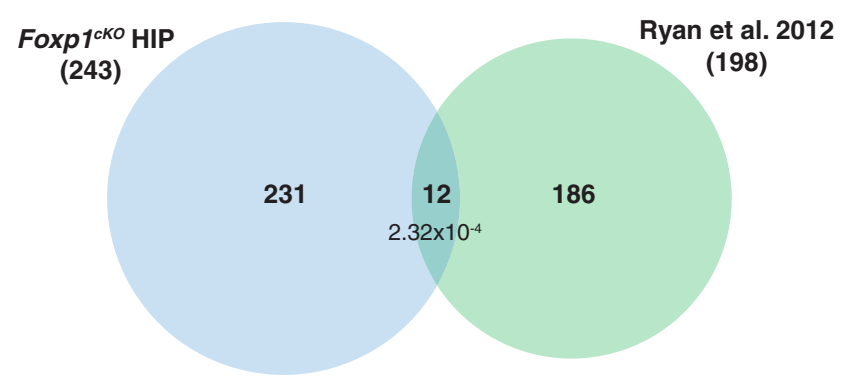

B

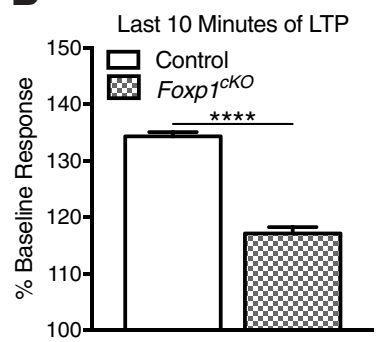

C

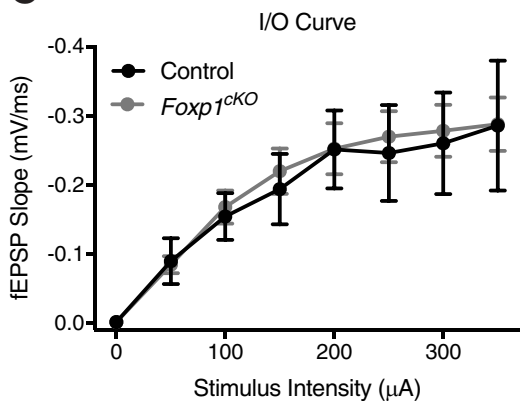

E

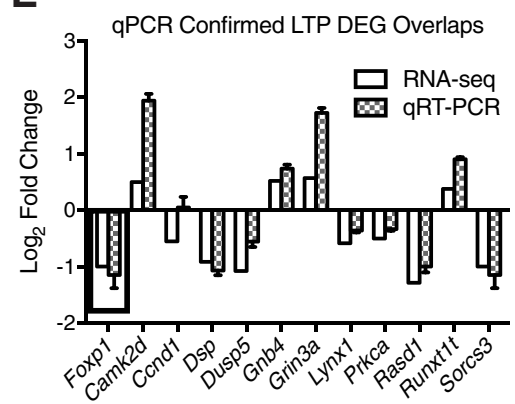

Figure 8. Altered hippocampal synaptic plasticity in $F$ oxp $1^{\mathrm{CK} 0}$ mice. $A, B$, In response to high-frequency stimulation (HFS), there is no difference in the initial magnitude of $L T P$ in $F$ oxp $1^{\mathrm{ck0}} \mathrm{CA} 1$ neurons $(\boldsymbol{A})$, but there is a difference in the LTP response during the last 10 min of stimulation $(\boldsymbol{B})$. Data are represented as means \pm SEM. $n=15$ control recordings; $n=20$ Foxp $7^{\mathrm{ck} 0}$ recordings, Student's $t$ test, compared between genotypes. C, Basal synaptic transmission is unchanged between Foxp $7^{\mathrm{ckO} 0}$ and littermate control mice as measured by input/output curves comparing stimulus intensity to fEPSP slope in CA1 pyramidal neurons. Data are represented as means \pm SEM. $n=15$ control recordings; $n=19$ Foxp ${ }^{\text {cko }}$ recordings. $p=0.63$, two-way ANOVA, compared between genotypes. D, Significant overlaps between Foxp ${ }^{\mathrm{c} K 0}$ HIP DEGs and LTP maintenance DEGs (Ryan et al., 2012). A total of 12 genes overlapped between the Foxp ${ }^{\mathrm{cKO}}$ HIP and LTP maintenance

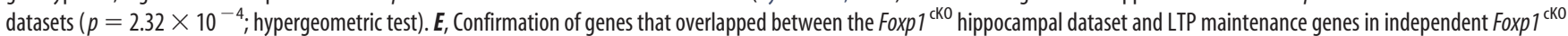
hippocampal samples using qPCR. Box insert highlights Foxp1. With the exception of Cend1, Dusp5, and Sorcs3, all qPCR values are significant at $p<0.05$ (Student's $t$ test, compared with control levels, normalized to $\beta$-actin). Data are represented as means \pm SEM. $n=3$ control mice; $n=3$ Foxp $1^{\text {cko }}$ mice.

tion in Foxp1 $1^{\text {cKO }}$ mice is sufficient to allow for associations between discrete, easily recognizable elements of the contextual conditioning environment and the unconditioned stimulus (Maren, 2001). Finally, these opposing results could be explained by the simple idea that Foxp $1^{\text {cKO }}$ mice might not be able to meet the cognitive load necessary for complex spatial tasks, but are able to meet the cognitive load required for fear-based tasks, which involve more salient conditioning. The amygdala is critically involved in cue-based fear learning (Puzzo et al., 2014; Tovote et al., 2015) and there is limited expression of Foxp 1 in the amygdala (Ferland et al., 2003). However, the intact cue-dependent fear conditioning in Foxp $1^{\mathrm{cKO}}$ mice (Fig. $5 A, B$ ) suggests that the role the hippocampal-amygdala circuit plays in this task is spared with loss of Foxp1.

The intact set-shifting learning that we observed in Foxp $1^{\text {cKO }}$ mice (Fig. 5C,D) suggests that, whereas Foxp1 expression is almost completely absent in the neocortex of these animals, this expression loss does not affect other, broader types of learning. In addition, the spared set-shifting learning in Foxp $1^{\mathrm{cKO}}$ mice (Fig. $5 C, D)$ could represent compensation by subcortical circuits in which Foxp1 expression is preserved. Regardless, these results need to be interpreted carefully because we cannot fully rule out other learning defects due to neocortical loss of Foxp1 that were not tested in this study. Together, our results suggest that Foxp $1^{\mathrm{cKO}}$ mice exhibit a specific deficit in complex, hippocampal-based spatial tasks.

Mice with full-brain loss of Foxp1 also display hyperactivity, impaired spatial learning, and impaired social behaviors (Bacon et al., 2015). Conversely, unlike the results presented here (Fig. $8 A, B)$, hippocampal neuron excitability is reduced and hippocampal LTP is unaltered in full-brain Foxp1 knock-out mice
(Bacon et al., 2015). However, the study of full-brain Foxp1 knock-out mice used a weaker protocol for LTP induction (Bacon et al., 2015) than our study, so it is possible that such a protocol may not have recruited the same plasticity maintenance mechanisms recruited in this study.

The Foxp $1^{\mathrm{cKO}}$ hippocampus dataset possessed fewer DEGs than the Foxp1 ${ }^{+/-}$hippocampus RNA-seq dataset (Fig. 6C). This result was surprising to us because we expected complete loss of Foxp1 to yield greater disruptions to the hippocampal transcriptome than Foxp 1 haploinsufficiency. The larger number of hippocampal DEGs observed in Foxp $1^{+/-}$mice could be explained by improper signaling to the hippocampus from subcortical regions that also experience reduced Foxp1 levels. Using an available single-cell RNA-seq dataset (Zeisel et al., 2015), we found that Foxp $1^{\mathrm{cKO}}$ hippocampal DEGs were most significantly enriched for genes expressed in CA 1 and Foxp $1^{\mathrm{cKO}}$ neocortical DEGs were most significantly enriched for genes expressed in pyramidal neurons of somatosensory cortex (Fig. 6-2, available at https://doi.org/10.1523/JNEUROSCI.1005-17.2017.f6-2). Therefore, our data suggest that loss of Foxp1 leads to disruptions in the expression of genes important for cellular identity in both brain regions. The DEGs that result from loss of Foxp1 in the hippocampus also indicate changes in pathways known to be important in hippocampal LTP, synaptic signaling, and spatial memory (Fig. 6A). We observed no differences in the basal synaptic transmission in the Foxp $1^{\mathrm{cKO}}$ mouse hippocampus (Fig. $8 C$ ), suggesting that the diminished LTP maintenance that we recorded in the Foxp $1^{\mathrm{cKO}} \mathrm{CA} 1$ region (Fig. $8 A, B$ ) was due to the dysregulation of downstream signaling networks and not to alterations to baseline synaptic function (Kotaleski and Blackwell, 
2010). This is supported by the finding that our Foxp $1^{\text {cKO }}$ hippocampal RNA-seq dataset overlapped significantly with a hippocampal maintenance gene list (Fig. 8D; Ryan et al., 2012).

Future studies that test directly the involvement of genes regulated by Foxp1 in LTP maintenance would be compelling, especially because disrupted synaptic signaling has a widely known role in explaining the etiology of ASD and ID (Santini and Klann, 2014). Nevertheless, it is unclear whether restoration of any one downstream gene (or combination of genes) would be sufficient to rescue both the physiological and behavioral deficits seen in Foxp $1^{\mathrm{cKO}}$ mice. The generation of additional brain-regionspecific Foxp1 knock-out mice will address whether the expression of Foxp1 in the hippocampus is required for the observed behavioral deficits. Moreover, Foxp1 expression in the striatum is intact in the Foxp $1^{\mathrm{CKO}}$ mice detailed here (Fig. $1 A, B$ ), yet there are robust striatal deficits in heterozygous Foxp1 knock-out mice (Araujo et al., 2015) and brain-wide Foxp1 knock-out mice (Bacon et al., 2015). Therefore, a Foxp1 knock-out mouse that primarily targets the striatum will be important for understanding the contributions of Foxp1 to the complex behavioral phenotypes associated with ASD and ID.

In summary, this study is an important step toward completing our understanding of the region-specific roles of FoxP1 within the brain. Because FOXP1 is among the most salient ASD and ID genes, any knowledge of FOXP1 function should contribute to our understanding of ASD and ID pathophysiology. Indeed, an in-depth understanding of the basic mechanisms of brain development and function as it pertains to certain neurodevelopmental disease-relevant genes such as FOXP1 will be critical to designing effective therapeutics for the resultant conditions.

\section{References}

Ageranioti-Bélanger S, Brunet S, D’Anjou G, Tellier G, Boivin J, Gauthier M (2012) Behaviour disorders in children with an intellectual disability. Paediatr Child Health 17:84-88. CrossRef Medline

Anders S, Huber W (2010) Differential expression analysis for sequence count data. Genome Biol 11:R106. CrossRef Medline

Anders S, Pyl PT, Huber W (2015) HTSeq-a Python framework to work with high-throughput sequencing data. Bioinformatics 31:166-169. CrossRef Medline

Andrews S (2010) FastQC: a quality control tool for high throughput sequence data. Available at: http://www.bioinformatics.babraham.ac.uk/ projects/fastqc.

Araujo DJ, Anderson AG, Berto S, Runnels W, Harper M, Ammanuel S, Rieger MA, Huang HC, Rajkovich K, Loerwald KW, Dekker JD, Tucker HO, Dougherty JD, Gibson JR, Konopka G (2015) FoxP1 orchestration of ASD-relevant signaling pathways in the striatum. Genes Dev 29:20812096. CrossRef Medline

Bacon C, Rappold GA (2012) The distinct and overlapping phenotypic spectra of FOXP1 and FOXP2 in cognitive disorders. Hum Genet 131: 1687-1698. CrossRef Medline

Bacon C, Schneider M, Le Magueresse C, Froehlich H, Sticht C, Gluch C, Monyer H, Rappold GA (2015) Brain-specific Foxp1 deletion impairs neuronal development and causes autistic-like behaviour. Mol Psychiatry 20:632-639. CrossRef Medline

Bock NA, Nieman BJ, Bishop JB, Mark Henkelman R (2005) In vivo multiple-mouse MRI at 7 tesla. Magn Reson Med 54:1311-1316. CrossRef Medline

Bolger AM, Lohse M, Usadel B (2014) Trimmomatic: a flexible trimmer for Illumina sequence data. Bioinformatics 30:2114-2120. CrossRef Medline

Carlson GC, Lin RE, Chen Y, Brookshire BR, White RS, Lucki I, Siegel SJ, Kim SF (2016) Dexras1 a unique ras-GTPase interacts with NMDA receptor activity and provides a novel dissociation between anxiety, working memory and sensory gating. Neuroscience 322:408-415. CrossRef Medline

Chen JA, Peñagarikano O, Belgard TG, Swarup V, Geschwind DH (2015) The emerging picture of autism spectrum disorder: genetics and pathology. Annu Rev Pathol 10:111-144. CrossRef Medline

Cho KK, Hoch R, Lee AT, Patel T, Rubenstein JL, Sohal VS (2015) Gamma rhythms link prefrontal interneuron dysfunction with cognitive inflexibility in Dlx5/6(+/-) mice. Neuron 85:1332-1343. CrossRef Medline

Cho YH, Friedman E, Silva AJ (1999) Ibotenate lesions of the hippocampus impair spatial learning but not contextual fear conditioning in mice. Behav Brain Res 98:77-87. Medline

Deacon RM (2006) Assessing nest building in mice. Nat Protoc 1:11171119. CrossRef Medline

de la Torre-Ubieta L, Won H, Stein JL, Geschwind DH (2016) Advancing the understanding of autism disease mechanisms through genetics. Nat Med 22:345-361. CrossRef Medline

de Quervain DJ, Papassotiropoulos A (2006) Identification of a genetic cluster influencing memory performance and hippocampal activity in humans. Proc Natl Acad Sci U S A 103:4270-4274. CrossRef Medline

Dobin A, Davis CA, Schlesinger F, Drenkow J, Zaleski C, Jha S, Batut P, Chaisson M, Gingeras TR (2013) STAR: ultrafast universal RNA-seq aligner. Bioinformatics 29:15-21. CrossRef Medline

Dorr AE, Lerch JP, Spring S, Kabani N, Henkelman RM (2008) High resolution three-dimensional brain atlas using an average magnetic resonance image of 40 adult C57Bl/6J mice. Neuroimage 42:60-69. CrossRef Medline

Ellegood J, et al. (2015) Clustering autism: using neuroanatomical differences in 26 mouse models to gain insight into the heterogeneity. Mol Psychiatry 20:118-125. CrossRef Medline

Fakhoury M (2015) Autistic spectrum disorders: A review of clinical features, theories and diagnosis. Int J Dev Neurosci 43:70-77. CrossRef Medline

Feng X, Ippolito GC, Tian L, Wiehagen K, Oh S, Sambandam A, Willen J, Bunte RM, Maika SD, Harriss JV, Caton AJ, Bhandoola A, Tucker PW, $\mathrm{Hu} \mathrm{H}$ (2010) Foxp1 is an essential transcriptional regulator for the generation of quiescent naive $\mathrm{T}$ cells during thymocyte development. Blood 115:510-518. CrossRef Medline

Ferland RJ, Cherry TJ, Preware PO, Morrisey EE, Walsh CA (2003) Characterization of Foxp2 and Foxp1 mRNA and protein in the developing and mature brain. J Comp Neurol 460:266-279. CrossRef Medline

Genovese CR, Lazar NA, Nichols T (2002) Thresholding of statistical maps in functional neuroimaging using the false discovery rate. Neuroimage 15:870-878. CrossRef Medline

Geschwind DH, State MW (2015) Gene hunting in autism spectrum disorder: on the path to precision medicine. Lancet Neurol 14:1109-1120. CrossRef Medline

Gorski JA, Talley T, Qiu M, Puelles L, Rubenstein JL, Jones KR (2002) Cortical excitatory neurons and glia, but not GABAergic neurons, are produced in the Emx1-expressing lineage. J Neurosci 22:6309-6314. Medline

Heisler JM, Morales J, Donegan JJ, Jett JD, Redus L, O’Connor JC (2015) The attentional set shifting task: a measure of cognitive flexibility in mice. J Vis Exp 96:51944. CrossRef Medline

Hernandez RN, Feinberg RL, Vaurio R, Passanante NM, Thompson RE, Kaufmann WE (2009) Autism spectrum disorder in fragile X syndrome: a longitudinal evaluation. Am J Med Genet A 149A:1125-1137. CrossRef Medline

Hisaoka T, Nakamura Y, Senba E, Morikawa Y (2010) The forkhead transcription factors, Foxp1 and Foxp2, identify different subpopulations of projection neurons in the mouse cerebral cortex. Neuroscience 166:551563. CrossRef Medline

Holy TE, Guo Z (2005) Ultrasonic songs of male mice. PLoS Biol 3:e386. CrossRef Medline

Huynh DP, Maalouf M, Silva AJ, Schweizer FE, Pulst SM (2009) Dissociated fear and spatial learning in mice with deficiency of ataxin-2. PLoS One 4:e6235. CrossRef Medline

Iossifov I, et al. (2014) The contribution of de novo coding mutations to autism spectrum disorder. Nature 515:216-221. CrossRef Medline

Kaestner KH, Knochel W, Martinez DE (2000) Unified nomenclature for the winged helix/forkhead transcription factors. Genes Dev 14:142-146. Medline

Kotaleski JH, Blackwell KT (2010) Modelling the molecular mechanisms of synaptic plasticity using systems biology approaches. Nat Rev Neurosci 11:239-251. CrossRef Medline

Kubota M, Murakoshi T, Saegusa H, Kazuno A, Zong S, Hu Q, Noda T, Tanabe T (2001) Intact LTP and fear memory but impaired spatial memory in mice lacking $\mathrm{Ca}(\mathrm{v}) 2.3$ (alpha(IE)) channel. Biochem Biophys Res Commun 282:242-248. CrossRef Medline

Kumar A (2011) Long-term potentiation at CA3-CA1 hippocampal syn- 
apses with special emphasis on aging, disease, and stress. Front Aging Neurosci 3:7. CrossRef Medline

Langfelder P, Horvath S (2008) WGCNA: an R package for weighted correlation network analysis. BMC Bioinformatics 9:559. CrossRef Medline

Le Fevre AK, Taylor S, Malek NH, Horn D, Carr CW, Abdul-Rahman OA, O’Donnell S, Burgess T, Shaw M, Gecz J, Bain N, Fagan K, Hunter MF (2013) FOXP1 mutations cause intellectual disability and a recognizable phenotype. Am J Med Genet A 161A:3166-3175. CrossRef Medline

Leitner Y (2014) The co-occurrence of autism and attention deficit hyperactivity disorder in children: what do we know? Front Hum Neurosci 8:268. CrossRef Medline

Lerch JP, Carroll JB, Spring S, Bertram LN, Schwab C, Hayden MR, Henkelman RM (2008) Automated deformation analysis in the YAC128 Huntington disease mouse model. Neuroimage 39:32-39. CrossRef Medline

Lerch JP, Sled JG, Henkelman RM (2011) MRI phenotyping of genetically altered mice. Methods Mol Biol 711:349-361. CrossRef Medline

Li X, Xiao J, Fröhlich H, Tu X, Li L, Xu Y, Cao H, Qu J, Rappold GA, Chen JG (2015) Foxp1 regulates cortical radial migration and neuronal morphogenesis in developing cerebral cortex. PLoS One 10:e0127671. CrossRef Medline

Love MI, Huber W, Anders S (2014) Moderated estimation of fold change and dispersion for RNA-seq data with DESeq2. Genome Biol 15:550. CrossRef Medline

Lozano R, Vino A, Lozano C, Fisher SE, Deriziotis P (2015) A de novo FOXP1 variant in a patient with autism, intellectual disability and severe speech and language impairment. Eur J Hum Genet 23:1702-1707. CrossRef Medline

Lynch MA (2004) Long-term potentiation and memory. Physiol Rev 84:87136. CrossRef Medline

Maren S (2001) Neurobiology of Pavlovian fear conditioning. Annu Rev Neurosci 24:897-931. CrossRef Medline

McCarthy DJ, Chen Y, Smyth GK (2012) Differential expression analysis of multifactor RNA-Seq experiments with respect to biological variation. Nucl Acids Res 40:4288-4297. CrossRef Medline

Mullins C, Fishell G, Tsien RW (2016) Unifying views of autism spectrum disorders: a consideration of autoregulatory feedback loops. Neuron 89: 1131-1156. CrossRef Medline

Nieman BJ, Bock NA, Bishop J, Sled JG, Josette Chen X, Mark Henkelman R (2005) Fast spin-echo for multiple mouse magnetic resonance phenotyping. Magn Reson Med 54:532-537. CrossRef Medline

Nieman BJ, Flenniken AM, Adamson SL, Henkelman RM, Sled JG (2006) Anatomical phenotyping in the brain and skull of a mutant mouse by magnetic resonance imaging and computed tomography. Physiol Genomics 24:154-162. Medline

Park HR, Lee JM, Moon HE, Lee DS, Kim BN, Kim J, Kim DG, Paek SH (2016) A short review on the current understanding of autism spectrum disorders. Exp Neurobiol 25:1-13. CrossRef Medline

Plummer JT, Gordon AJ, Levitt P (2016) The genetic intersection of neurodevelopmental disorders and shared medical comorbidities: relations that translate from bench to bedside. Front Psychiatry 7:142. CrossRef Medline

Portfors CV, Perkel DJ (2014) The role of ultrasonic vocalizations in mouse communication. Curr Opin Neurobiol 28:115-120. CrossRef Medline

Precious SV, Kelly CM, Reddington AE, Vinh NN, Stickland RC, Pekarik V, Scherf C, Jeyasingham R, Glasbey J, Holeiter M, Jones L, Taylor MV, Rosser AE (2016) FoxP1 marks medium spiny neurons from precursors to maturity and is required for their differentiation. Exp Neurol 282:9-18. CrossRef Medline

Puzzo D, Lee L, Palmeri A, Calabrese G, Arancio O (2014) Behavioral assays with mouse models of Alzheimer's disease: practical considerations and guidelines. Biochem Pharmacol 88:450-467. CrossRef Medline

Robinson MD, McCarthy DJ, Smyth GK (2010) edgeR: a Bioconductor package for differential expression analysis of digital gene expression data. Bioinformatics 26:139-140. CrossRef Medline

Ryan MM, Ryan B, Kyrke-Smith M, Logan B, Tate WP, Abraham WC, Williams JM (2012) Temporal profiling of gene networks associated with the late phase of long-term potentiation in vivo. PLoS One 7:e40538. CrossRef Medline
Sanders SJ, et al. (2015) Insights into autism spectrum disorder genomic architecture and biology from 71 risk loci. Neuron 87:1215-1233. CrossRef Medline

Santini E, Klann E (2014) Reciprocal signaling between translational control pathways and synaptic proteins in autism spectrum disorders. Sci Signal 7:re10. CrossRef Medline

Shannon P, Markiel A, Ozier O, Baliga NS, Wang JT, Ramage D, Amin N, Schwikowski B, Ideker T (2003) Cytoscape: a software environment for integrated models of biomolecular interaction networks. Genome Res 13:2498-2504. CrossRef Medline

Shoji H, Hagihara H, Takao K, Hattori S, Miyakawa T (2012) T-maze forced alternation and left-right discrimination tasks for assessing working and reference memory in mice. J Vis Exp 60: pii: 3300. CrossRef Medline

Silverman JL, Yang M, Lord C, Crawley JN (2010) Behavioural phenotyping assays for mouse models of autism. Nat Rev Neurosci 11:490-502. CrossRef Medline

Spiteri E, Konopka G, Coppola G, Bomar J, Oldham M, Ou J, Vernes SC, Fisher SE, Ren B, Geschwind DH (2007) Identification of the transcriptional targets of FOXP2, a gene linked to speech and language, in developing human brain. Am J Hum Genet 81:1144-1157. CrossRef Medline

State MW, Šestan N (2012) Neuroscience: the emerging biology of autism spectrum disorders. Science 337:1301-1303. CrossRef Medline

Steadman PE, Ellegood J, Szulc KU, Turnbull DH, Joyner AL, Henkelman RM, Lerch JP (2014) Genetic effects on cerebellar structure across mouse models of autism using a magnetic resonance imaging atlas. Autism Res 7:124-137. CrossRef Medline

Stessman HA, et al. (2017) Targeted sequencing identifies 91 neurodevelopmental-disorder risk genes with autism and developmental-disability biases. Nat Genet 49:515-526. CrossRef Medline

Supek F, Bošnjak M, Škunca N, Šmuc T (2011) REVIGO summarizes and visualizes long lists of gene ontology terms. PLoS One 6:e21800. CrossRef Medline

Takahashi JS, Kumar V, Nakashe P, Koike N, Huang HC, Green CB, Kim TK (2015) ChIP-seq and RNA-seq methods to study circadian control of transcription in mammals. Methods Enzymol 551:285-321. CrossRef Medline

Tamura S, Morikawa Y, Iwanishi H, Hisaoka T, Senba E (2004) Foxp1 gene expression in projection neurons of the mouse striatum. Neuroscience 124:261-267. CrossRef Medline

Tovote P, Fadok JP, Lüthi A (2015) Neuronal circuits for fear and anxiety. Nat Rev Neurosci 16:317-331. CrossRef Medline

Ullmann JF, Watson C, Janke AL, Kurniawan ND, Reutens DC (2013) A segmentation protocol and MRI atlas of the C57BL/6J mouse neocortex. Neuroimage 78:196-203. CrossRef Medline

van Steensel FJ, Bögels SM, Perrin S (2011) Anxiety disorders in children and adolescents with autistic spectrum disorders: a meta-analysis. Clin Child Fam Psychol Rev 14:302-317. CrossRef Medline

Vilches N, Spichiger C, Mendez N, Abarzua-Catalan L, Galdames HA, Hazlerigg DG, Richter HG, Torres-Farfan C (2014) Gestational chronodisruption impairs hippocampal expression of NMDA receptor subunits Grinlb/Grin3a and spatial memory in the adult offspring. PLoS One 9:e91313. CrossRef Medline

Vissers LE, Gilissen C, Veltman JA (2016) Genetic studies in intellectual disability and related disorders. Nat Rev Genet 17:9-18. CrossRef Medline

Vorhees CV, Williams MT (2006) Morris water maze: procedures for assessing spatial and related forms of learning and memory. Nat Protoc 1:848-858. CrossRef Medline

Wang B, Lin D, Li C, Tucker P (2003) Multiple domains define the expression and regulatory properties of Foxp1 forkhead transcriptional repressors. J Biol Chem 278:24259-24268. CrossRef Medline

Yamamoto J, Suh J, Takeuchi D, Tonegawa S (2014) Successful execution of working memory linked to synchronized high-frequency gamma oscillations. Cell 157:845-857. CrossRef Medline

Zeisel A, Muñoz-Manchado AB, Codeluppi S, Lönnerberg P, La Manno G, Juréus A, Marques S, Munguba H, He L, Betsholtz C, Rolny C, CasteloBranco G, Hjerling-Leffler J, Linnarsson S (2015) Brain structure. Cell types in the mouse cortex and hippocampus revealed by single-cell RNAseq. Science 347:1138-1142. CrossRef Medline 